\title{
The Timing of Response Onset and Offset in Macaque Visual Neurons
}

\author{
Wyeth Bair, ${ }^{1,2}$ James R. Cavanaugh, ${ }^{2}$ Matthew A. Smith,, ${ }^{2}$ and J. Anthony Movshon ${ }^{1,2}$ \\ ${ }^{1}$ Howard Hughes Medical Institute and ${ }^{2}$ Center for Neural Science, New York University, New York, New York 10003
}

We used fast, pseudorandom temporal sequences of preferred and antipreferred stimuli to drive neuronal firing rates rapidly between minimal and maximal across the visual system. Stimuli were tailored to the preferences of cells recorded in the lateral geniculate nucleus (magnocellular and parvocellular), primary visual cortex (simple and complex), and the extrastriate motion area MT. We found that cells took longer to turn on (to increase their firing rate) than to turn off (to reduce their rate). The latency difference (onset minus offset) varied from several to tens of milliseconds across cell type and stimulus class and was correlated with spontaneous or driven firing rates for most cell classes. The delay for response onset depended on the nature of the stimulus present before the preferred stimulus appeared, and may result from persistent inhibition caused by antipreferred stimuli or from suppression that followed the offset of the preferred stimulus. The onset delay showed three distinct types of dependence on the temporal sequence of stimuli across classes of cells, implying that suppression may accumulate or wear off with time. Onset latency is generally longer, can be more variable, and has marked stimulus dependence compared with offset latency. This suggests an important role for offset latency in assessing the speed of information transmission in the visual system and raises the possibility that signal offsets provide a timing reference for visual processing. We discuss the origin of the delay in onset latency compared with offset latency and consider how it may limit the utility of certain feedforward circuits.

Key words: macaque monkey; primary visual cortex; area MTIV5; lateral geniculate nucleus; spike timing; response latency; integration time; inhibition; spontaneous activity; temporal dynamics
In the earliest studies of neuronal response in the visual system, $\mathrm{ON}$ and OFF responses to light were recognized because light onset and offset both produced striking transient bursts of action potentials (Adrian and Matthews, 1927). If it had been otherwise, if cells had produced ON responses only and did not adapt so much, then perhaps response offsets would have received more attention in the last 75 years. If asked whether neurons in the visual system turn on or turn off sooner after a scene change, one might guess the former because a brief pulse of light causes a response that rises rapidly and decays slowly, outlasting the flash (Adrian and Matthews, 1927; Levick, 1973) or one might guess the latter because of the integration time required for a spiking neuron to reach threshold (Lapicque, 1907). The literature since then provides an ample account of the timing of response onsets (for review, see Nowak and Bullier, 1997) but is surprisingly quiet about response offset.

Here we study the latency of response onset and offset in several areas of the visual system because doing so offers a chance to interpret integration strategies in each area in the context of what is known about the other areas. To make this comparison across visual areas and cell classes, we attempt to generalize the notion of preferred, antipreferred, and null (or neutral) stimuli across three levels in the visual system. We optimized stimuli for

Received Aug. 17, 2001; revised Dec. 26, 2001; accepted Jan. 23, 2002.

This work was supported by National Institutes of Health Grant EY02017. Adam Kohn gave us comments on this manuscript, and he and Najib Majaj provided useful discussion and assisted with data collection. Hysell Oviedo and Alex Reyes provided insight from in vitro data, and Suzanne Fenstemaker provided assistance with histology.

Correspondence should be addressed to Wyeth Bair, Center for Neural Science, New York University, 4 Washington Place, Room 809, New York, NY 10003. E-mail: wyeth@cns.nyu.edu.

Copyright (C) 2002 Society for Neuroscience $\quad 0270-6474 / 02 / 223189-17 \$ 15.00 / 0$ the center-surround receptive fields (Barlow, 1953; Kuffler, 1953) of cells in the dorsal lateral geniculate nucleus (Hubel and Wiesel, 1961), for the spatial phase, orientation, and direction-selective (DS) cells in the primary visual cortex (V1) (Hubel and Wiesel, 1959), and for the DS cells of the extrastriate motion area MT/V5 (Zeki, 1974; Maunsell and Van Essen, 1983; Albright et al., 1984; Movshon et al., 1985). Sinusoidal gratings confined to the classical receptive field adequately activate all of these cell types (EnrothCugell and Robson, 1966; Movshon et al., 1978), but here we present them in rapid, random succession with their canonical opposites to facilitate the precise estimation of timing.

In the retina and LGN, there is probably no strong opponency between the ON and OFF pathways (Casagrande and Norton, 1991; Schiller, 1992). In V1, simple cells may receive push-pull feedforward inputs (Palmer and Davis, 1981; Heggelund, 1986; Ferster, 1988; Tolhurst and Dean, 1990; Hirsch et al., 1998; Troyer et al., 1998) (for review, see Ferster and Miller, 2000) or a less spatially specific inhibition (Borg-Graham et al., 1998; Troyer et al., 1998; Wielaard et al., 2001). Thus, rapid switching between preferred and counterphase stimuli would engage both pathways. Opponent circuits may operate in direction-selective cells (Sutherland, 1961; Barlow and Hill, 1963; Adelson and Bergen, 1985) (but see, Raymond and Braddick, 1996), but perhaps are different in V1 and MT (Qian and Andersen, 1994; Heeger et al., 1999).

For all cell types that we studied, response onset came later than response offset. We discuss how much of the onset delay is caused by neuronal integration time (defined to be the time from initial depolarization to spike threshold, Nowak and Bullier, 1997), how much can be attributed to inhibition, and how much is inherited with inputs from lower areas.

Some of these results have been published previously in abstract form (Bair et al., 2001). 


\section{MATERIALS AND METHODS}

Electrophysiology. We recorded extracellularly from single units in the dorsal LGN, primary visual cortex, and area MT of anesthetized, paralyzed, macaque monkeys (Macaca fascicularis). LGN, V1, and MT data were collected from 3, 16, and 13 monkeys, respectively. The numbers of animals for V1 and MT are large because data for this study was collected sporadically during experiments performed for other studies.

Detailed methods for this type of recording are available in Carandini et al. (1997) and O'Keefe and Movshon (1998). Experiments typically lasted 4-5 d during which anesthesia and paralysis were maintained with sufentanil citrate $\left(4-12 \mu \mathrm{g} \cdot \mathrm{kg}^{-1} \cdot \mathrm{hr}^{-1}\right)$ and vecuronium bromide (Norcuron; $0.1 \mathrm{mg} \cdot \mathrm{kg}^{-1} \cdot \mathrm{hr}^{-1}$ ), respectively, administered in lactated Ringer's solution. Inf usion solutions were mixed to $2.5 \%$ dextrose concentration to provide adequate nutrition, and infusion rate was adjusted to maintain fluid balance $\left(\sim 4-8 \mathrm{ml} \cdot \mathrm{kg}^{-1} \cdot \mathrm{hr}^{-1}\right)$. Artificial respiration with a mixture of $\mathrm{O}_{2}, \mathrm{~N}_{2} \mathrm{O}$, and $\mathrm{CO}_{2}$ was maintained with rate adjustments to keep expired $\mathrm{P}_{\mathrm{CO}_{2}}$ between 3.8 and $4.0 \%$. Body temperature was maintained near $37^{\circ} \mathrm{C}$ with a heating pad. EEG and electrocardiogram were monitored to ensure proper depth of anesthesia. The pupils were dilated with topical atropine, and the corneas protected with gaspermeable hard contact lenses. We refracted the eyes with supplementary lenses that were chosen to optimize neuronal responses to high spatial frequencies. All procedures conformed to guidelines of the New York University Animal Welfare Committee.

Tungsten-in-glass microelectrodes (Merrill and Ainsworth, 1972) were advanced with a hydraulic microdrive downward through a craniotomy of diameter 9-10 $\mathrm{mm}$. In some experiments, we used a mechanical microdrive system with quartz-platinum-tungsten microelectrodes (Thomas Recordings, Marburg, Germany). For V1 recordings, the craniotomy was typically centered $4 \mathrm{~mm}$ posterior to the lunate sulcus and $10 \mathrm{~mm}$ lateral to the midline. For LGN recordings, the craniotomy was centered $7 \mathrm{~mm}$ anterior to ear-bar zero and $11 \mathrm{~mm}$ lateral to the midline. For MT recordings, the craniotomy was centered $15 \mathrm{~mm}$ lateral to the midline, 4 $\mathrm{mm}$ posterior to the lunate sulcus, and the angle of advance was $20^{\circ}$ down and forward in the parasagittal plane. Action potentials were discriminated using a hardware dual-window time-amplitude discriminator (Bak, Germantown, MD) and time stamped at a resolution of $0.25 \mathrm{msec}$. Electrolytic lesions were made for histological verification and estimation of cortical layer. V1 neurons were recorded on the operculum and in the calcarine sulcus (typical receptive field eccentricities were $2-5^{\circ}$ and $8-24^{\circ}$, respectively). LGN cells were recorded from magnocellular and parvocellular layers at eccentricities ranging from 1 to $23^{\circ}$. MT cells were recorded at eccentricities ranging from 2 to $33^{\circ}$ but typically between 3 and $12^{\circ}$. For each cell whose action potential waveform was well isolated from the noise, we ran stimuli as described below.

Visual stimuli. Visual stimuli were generated by custom software on a CRS $2 / 2$ board (Cambridge Research Systems, Kent, UK) under the control of an Intel 86-based host computer. Stimuli were presented on a standard cathode ray tube at a resolution of $1024 \times 731$ pixels and a video frame rate of $100 \mathrm{~Hz}$ vertical refresh, with a mean luminance of $33 \mathrm{~cd} / \mathrm{m}^{2}$. The display was gamma-corrected with a lookup table. We used a front surface mirror to bring the receptive field (RF) of each cell into register with the center of a video monitor placed between 80 and $180 \mathrm{~cm}$ from the animal's eye, where it subtended between 10 and $22^{\circ}$. The graphics board that generated our stimulus also generated synchronization pulses that were time-locked to the start of the first frame of our stimulus. These pulses were time-stamped and recorded by the same system used for collecting action potential times.

The RF size was estimated by hand before beginning quantitative characterization with sinewave gratings. Quantitative estimates of RF properties were computed from tuning curves resulting from a series of randomly interleaved stimuli. Responses to drifting sinusoidal stimuli were quantified with DC (mean firing rate minus the baseline rate for a mean gray stimulus) and F1 (amplitude of the Fourier component of the response at the temporal frequency of the stimulus) tuning curves.

For V1 cells, drifting sinusoidal gratings were randomly interleaved under computer control to obtain response tuning curves first for orientation, next for spatial frequency, and then for temporal frequency. Next, we chose the smallest patch of optimized grating that elicited a response easily distinguishable from the spontaneous rate, and we alternated between adjusting the vertical and horizontal position of the patch by hand until the maximal response was obtained. At these coordinates, circular patches of various diameters were interleaved to obtain a tuning curve for size. The classical receptive field (CRF) of the V1 cell was defined to be the smallest circular patch that gave a response no $<95 \%$ of the maximum.

Cells were classified as simple or complex on the basis of the modulation index computed at the optimal spatial frequency (Skottun et al., 1991). For simple cells, the optimal phase of the grating was subsequently determined from an eight-point tuning curve for static, contrast modulated gratings. For complex cells and MT cells, we quantified directionality using the index $1-a / p$, where $p$ and $a$ were the responses to preferred direction (that which gave the highest response) and the antipreferred direction (opposite to preferred), respectively, in excess of the spontaneous rate (Maunsell and Van Essen, 1983). Cells were called DS if their directionality was $>0.5$.

LGN cells were characterized in a manner similar to V1 simple cells with two exceptions. First, LGN cells were mapped with a white noise stimulus in which squares in a $16 \times 16$ spatial grid were independently assigned zero or maximum luminance on every video frame on the basis of a pseudorandom number generator (Reid et al., 1997). The grid was scaled so that two or three boxes of the grid spanned the center of the LGN RF. A spatial map was computed using reverse-correlation to determine the location, size, and ON or OFF character of the RF center and surround. Second, orientation was set to be vertical (with rightward drift) unless our by-hand characterization or the white-noise spatial map indicated a significant orientation bias. Magnocellular and parvocellular cells (hereafter, m-cells and p-cells) were distinguished using a whitenoise stimulus, as described below.

Random sequence stimuli. After the initial characterization of a cell, we studied response timing using random binary and ternary stimulus sequences. For the binary sequences, either the preferred stimulus $(\mathrm{P})$ or the antipreferred stimulus (A) was presented on each video frame (i.e., every $10 \mathrm{msec}$ ). The choice between $\mathrm{A}$ and $\mathrm{P}$ was governed by a pseudorandom sequence generated using the ran 2 algorithm of Press et al. (1992). In later experiments, the randomization was governed by a binary m-sequence (Sutter, 1987; Reid et al., 1997). Ternary sequences, which included a null stimulus (N) were governed by the ran 2 algorithm and consisted of the equiprobable and independent presentation of $\mathrm{A}, \mathrm{N}$, or $\mathrm{P}$ on each video frame.

For LGN cells, we ran binary sequences with three types of $\mathrm{P}$ and $\mathrm{A}$ stimuli: spots, annuli, and gratings. (1) Spots: $\mathrm{P}$ was a disk of maximum or minimum luminance (for ON or OFF cells, respectively) presented on a gray background and confined to the central region of the RF determined from the reverse-correlation map. A was the disk of opposite contrast to P. (2) Annuli: P was an annulus of maximum or minimum luminance that was confined to the surround determined from the spatial reverse-correlation, and A was the annulus of opposite luminance. (3) Gratings: P was a centered, circular patch of sinusoidal grating having optimal spatial period and phase and covering the RF center and surround. A was counterphase to $\mathrm{P}$, i.e., it had $180^{\circ}$ opposite phase.

For V1 simple cells, we used two sets of P and A stimuli. For both sets, $\mathrm{P}$ was the optimal sinusoidal grating confined to the CRF (see above), and A was either counterphase or orthogonally oriented to P. We will refer to these two stimuli as the phase and orientation stimuli, respectively. For V1 complex DS cells and for MT cells, P and A were optimal gratings that differed in their direction of movement: $\mathrm{P}$ moved in the preferred direction, and A moved in the opposite direction. The amount of movement between video frames was typically $90^{\circ}$ of phase but was set to $45^{\circ}$ if the cell responded poorly to $90^{\circ}$ movements.

LGN m- and p-cells were distinguished on the basis of the presence of contrast gain control (of the type described by Shapley and Victor, 1978) in m-cells and its absence in p-cells (Benardete et al., 1992; Lee et al., 1994; Lee, 1996; Benardete and Kaplan, 1997, 1999; Levitt et al., 2001). Classification was based on the time-domain kernels (Benardete and Kaplan, 1997, 1999) computed for the binary counterphase stimulus and always agreed with our assessment on the basis of contrast sensitivity, transience, temporal resolution, and estimates of the laminar location of the recording.

Data analysis. For all analyses, the times of action potentials were expressed in milliseconds relative to the time at which the raster scan of the video display illuminated the center of the screen, where each neuronal receptive field had been centered. We determined the timing of our stimulus relative to the video synchronization pulses by plotting the luminance at the center of the screen (measured with a photometer) on an oscilloscope that was triggered by the video synchronization pulses. We then measured the timing of our data collection system by passing the video synchronization pulses through the same amplifiers and spike discrimination hardware that we used to detect action potentials. These 

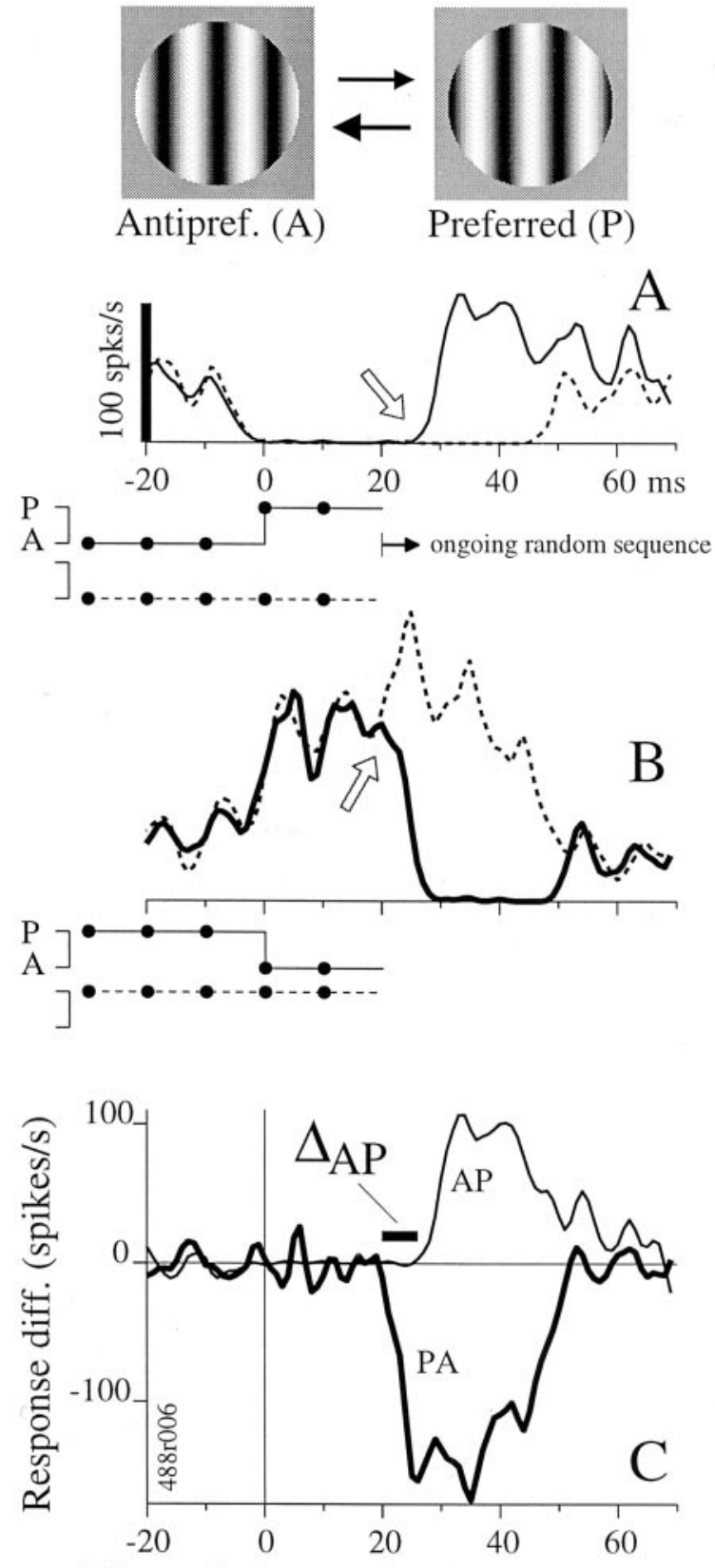

Time relative to stimulus transition (ms)

Figure 1. The estimation and comparison of response timing for turning on and turning off are demonstrated for an LGN p-cell. Top, Stimulus icons show preferred and antipreferred stimuli, $\mathrm{P}$ and $\mathrm{A}$, one of which was chosen randomly for presentation every $10 \mathrm{msec}$. $A$, Average firing rate versus time is plotted for two $50 \mathrm{msec}$ stimulus sequences, which are depicted below the abscissa. Solid lines indicate the stimulus and response for a transition from A to $\mathrm{P}$ (i.e., a change from the left to right stimulus icon, top), whereas dashed lines indicate the reference stimulus, $50 \mathrm{msec}$ of $\mathrm{A}$, and its response. Time 0 is when the transition to $\mathrm{P}$ occurred. Response latency was $\sim 30 \mathrm{msec}$; therefore, the first and last $20 \mathrm{msec}$ of the response traces are averages of responses to a random set of sequences that occurred before and after the $50 \mathrm{msec}$ trigger sequences (see arrow and label ongoing random sequence) and should not be confused with spontaneous firing rate. Epochs of A were associated with near zero firing rate, and the onset of $\mathrm{P}$ caused a rapid rate increase (solid response curve). Response curves were based on 253 occurrences of the stimulus sequences (see Materials and Methods). B, Responses of the same cell to the PA transition (a change from the right to left stimulus icon, top) are shown in the format of $A$. Firing rate was high for $\mathrm{P}$ epochs and dropped rapidly after the transition to A. Response curves were based on 253 occurrences of the stimulus sequences. $C$, The difference between the two measurements allowed us to compensate all spike times for the delays associated with stimulus generation and data collection.

We estimated the mean instantaneous firing rate (i.e., the peristimulus time histogram at the millisecond resolution) associated with particular stimulus patterns that occurred at random in our binary and ternary sequences. For example, the sequence AP indicates $30 \mathrm{msec}$ (three video frames) of the antipreferred stimulus followed by $20 \mathrm{msec}$ (two frames) of the preferred stimulus. The time of occurrence of the transition, defined to be the time of appearance of the first frame of $\mathrm{P}$, was taken as the reference time $(t=0)$. Spike train segments for each occurrence of a stimulus pattern were aligned to the reference time and averaged to estimate the mean instantaneous firing rate associated with that pattern. Average responses to stimulus transitions were always compared with the response for a reference pattern (the reference response) that had no transition. For example, the reference stimulus pattern for AP was 50 msec (five frames) of A. Figure 1 shows examples of responses to stimulus transitions and reference responses. Traces were smoothed with a Gaussian of SD $1 \mathrm{msec}$ before further analysis.

The response difference trace for a stimulus transition was computed by subtracting the reference response from the response to the transition. Response onset latency was determined automatically by finding the maximum point on the response curve (or on the response difference curve) and searching backwards in time from the maximum for the first point that was above $5 \%$ of the maximum response. A similar procedure was used to find response offset latency, except the minimum point and the 5\% drop to minimum were used. We also computed latencies for the rise (and fall) to $50 \%$ and found that our results were not significantly changed.

Our measure of the timing difference for turning on relative to turning off was $\Delta_{\mathrm{AP}}$, the onset latency for the response to the AP transition minus the offset latency for the response to the P-to-A (PA) transition. For ternary sequences, which contained antipreferred and null (in addition to preferred) stimuli, we computed $\Delta_{\mathrm{AP}}$ and a comparable measure for the $\mathrm{N}$ stimuli, $\Delta_{\mathrm{NP}}$, which we defined as the latency for turning on from $\mathrm{N}$ minus the latency for turning off based on the PA transition. The PA transition latency was used for the off reference time for both $\Delta_{\mathrm{NP}}$ and $\Delta_{\mathrm{AP}}$ because it was on average not different from, yet less variable than, the P-to-N (PN) latency, and it provided a common reference for both measurements.

\section{RESULTS}

We measured response timing for 31 cells in the LGN (14 p-cells and 17 m-cells), 63 cells in V1 (18 simple, 11 complex non-DS, 34 complex DS), and 39 DS cells in MT. All cells were tested with random, binary sequences of visual stimuli in which either the preferred stimulus $\mathrm{P}$ or the antipreferred stimulus $\mathrm{A}$ appeared every $10 \mathrm{msec}$. We will begin by demonstrating the computation of our response timing measurements for the binary stimulus and will summarize these measurements across cell types. For each cell type, we will show how timing correlated with spontaneous and evoked firing rates. We will then assess the influence of antipreferred stimuli on response timing by comparing them with $\mathrm{N}$, which are hypothetically neutral. Finally, we show that timing is influenced in different ways across areas and cell types by the temporal history of the stimulus.

\section{Latency for response onsets and offsets}

Figure 1 demonstrates our method for measuring onset and offset latency for an LGN p-cell that was tested with the phase stimulus. Every $10 \mathrm{msec}$, either the preferred stimulus $\mathrm{P}$ (the optimal sinusoidal grating) or the antipreferred stimulus A (the grating

$\leftarrow$

response to the AP transition and to its reference stimulus (in $A$, solid minus dotted line) is plotted here as the thin line. The analogous difference between the traces in $B$ is plotted as the thick line. These response difference traces allow direct comparison of the timing of the onset of signals evoked by the AP and PA stimulus transitions. We defined $\Delta_{\mathrm{AP}}$ to be the difference in timing between the onsets of the AP and PA response (thick bar; see Materials and Methods). 
opposite in phase) was presented (Fig. 1, Top, right and left icons). We estimated the onset latency by comparing the response for the A-to-P (AP) transition with that for a reference stimulus that contained no transition to P. The AP transition was defined to be $30 \mathrm{msec}$ of A followed by $20 \mathrm{msec}$ of $\mathrm{P}$, and the reference stimulus, lacking the transition, was $50 \mathrm{msec}$ of A (Fig. $1 \mathrm{~A}$, solid and dashed lines, respectively; below abscissa). Because these 50 msec stimulus sequences appeared in an ongoing random sequence, the stimuli preceding and after them were random. In Figure $1 A$, the time at which the response to the AP transition (solid line) turns upward (open arrow) from the reference response (dashed line) is the onset latency. The latency is $\sim 27 \mathrm{msec}$ relative to the stimulus transition, which occurs at time 0 . The upturn in the reference trace (dashed line) near $45 \mathrm{msec}$ results from responses to random sequences that followed the trigger sequence and does not influence our timing measurements. We estimated the offset latency in a similar manner from the response to the P-to-A (PA) transition (30 msec of P followed by $20 \mathrm{msec}$ of $\mathrm{A})$ and its reference stimulus (50 msec of $\mathrm{P}$ ) (Fig. $1 B)$. The response to the PA transition diverges from the reference response $\sim 25 \mathrm{msec}$ after the stimulus transition ( $B$, open arrow). To facilitate the comparison of onset and offset latencies, we plotted the AP response minus its reference response together with the PA response minus its reference. These response difference plots (Fig. 1C) make it apparent that the response decrease for the PA transition (thick line) occurred before the response increase for the AP transition (thin line) for this neuron.

Figure 2 shows response difference plots for cells from LGN, $\mathrm{V} 1$, and MT that were tested with random, binary sequences of $\mathrm{P}$ and A stimuli that were suited to the properties of the cells on the

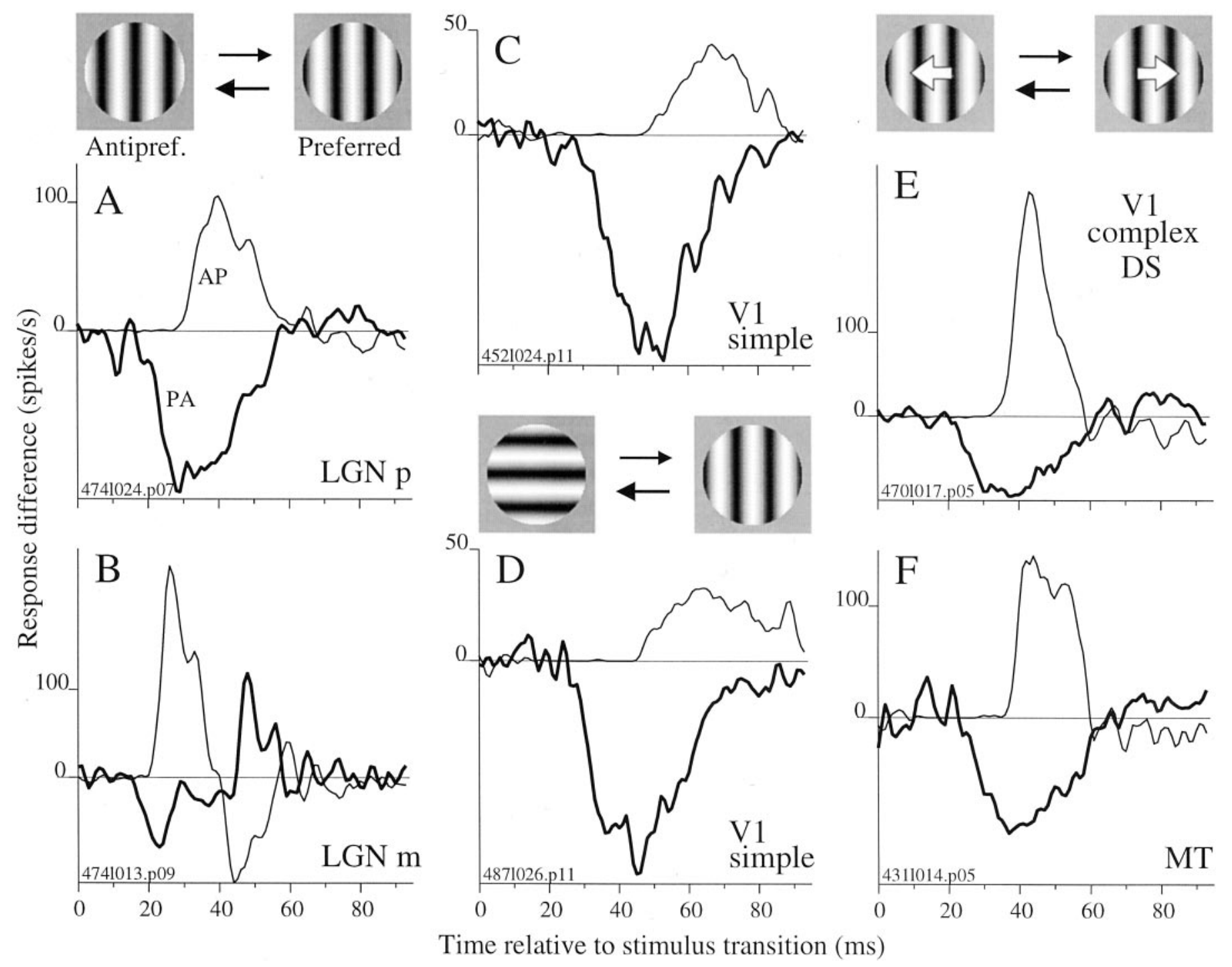

Figure 2. Response decreases occurred sooner than response increases when switching between $\mathrm{P}$ and A. For five classes of neurons, response difference plots (defined in Fig. 1) for PA and AP transitions (thick and thin lines, respectively) are shown for example cells responding to binary random sequences of optimized sinusoidal grating stimuli. $A$, Difference plots for an LGN p-cell responding to the phase stimulus (transitions between opposite phases, icons, top of left column) show that the PA response occurred before the AP response. B, For an LGN m-cell responding to the phase stimulus, a smaller timing asymmetry is present. The sign reversal at $\sim 40 \mathrm{msec}$ resulted from the combination of the transient nature of the m-cell response and the chance transitions that followed the reference stimuli (e.g., $50 \mathrm{msec}$ of A was sometimes followed by $\mathrm{P}$ and vice versa). $C$, Difference plots for a V1 simple cell responding to the phase stimulus show a timing asymmetry larger than that observed for the LGN cells in $A$ and $B$. $D$, Responses of a V1 cell to transitions between orthogonal orientations (icons in center) also show a large timing asymmetry. Responses of a V1 complex DS cell $(E)$ and an MT cell $(F)$ to transitions between opposite directions of motion (icons, top of right column) show a timing asymmetry as well. 


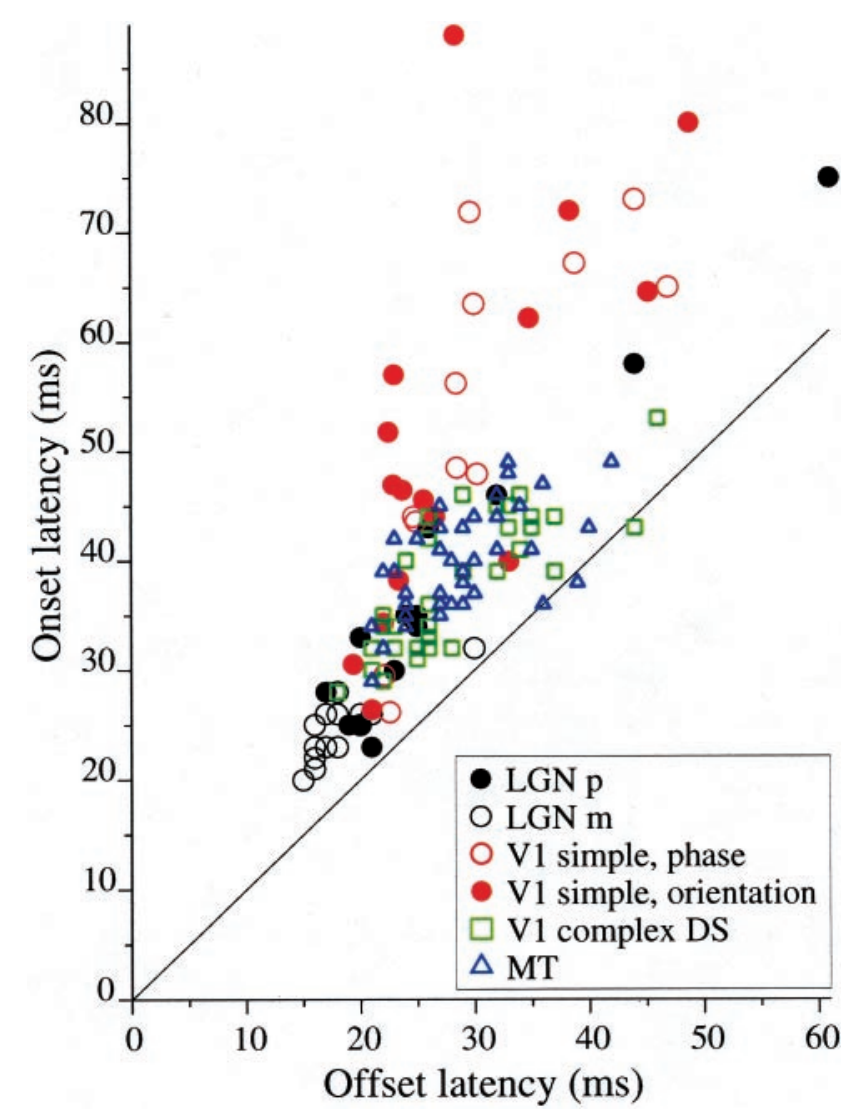

Figure 3. A comparison of onset and offset latencies across cell types and stimulus categories. The latency of the response to the transition from antipreferred to preferred (onset latency) is plotted against the latency of the response to the opposite stimulus transition (preferred to antipreferred, offset latency). Nearly all points fell above the diagonal line of equality, indicating that onset latency is longer than offset latency. The mean onset and offset latencies for each cell class and stimulus type are reported in Table 1 .

basis of initial characterization with sinusoidal stimuli. The phase stimulus, presented to LGN p- and m-cells and to V1 simple cells ( $A-C$, respectively), covered the classical center and surround of the LGN RF and was restricted to the CRF for V1 cells. V1 simple cells were also tested with the orientation stimulus $(D)$, which differed from the phase stimulus only by a $90^{\circ}$ rotation of the antipreferred sinusoid. V1 complex DS cells $(E)$ and MT cells $(F)$ were tested with the direction stimulus (icon above $E$ ), which was an optimally oriented grating that moved in either the preferred or opposite direction every $10 \mathrm{msec}$. For each example in Figure 2, the response difference trace for the PA transition (thick lines) dropped from zero before the trace for the AP transition rose (thin lines). We quantified the offset and onset times for each cell from the respective response difference plots as the time to reach $5 \%$ of the maximum excursion from zero (see Materials and Methods).

Onset latency is plotted against offset latency for all cells in Figure 3. The points fell mainly above the diagonal line of equality, indicating that offset time was less than onset time. For each cell class, onset and offset times were significantly correlated (Pearson's $r$ ranged from 0.60 to $0.97, p<0.004$, for each cell class). Our median LGN onset latencies (24 and $34 \mathrm{msec}$ for $\mathrm{m}$ and p-cells, respectively) fell within the range of medians reported by Maunsell et al. (1999), and our minimum onset latency (20 msec) was larger than theirs (16-18 msec). In V1, our shortest onset latencies $(26-30 \mathrm{msec})$ were consistent with the shortest reported in the literature (Bartlett and Doty, 1974; Maunsell and Gibson, 1992; Nowak et al., 1995). For MT, however, 5 of 39 cells responded before $35 \mathrm{msec}$, which was faster than most published minimum latencies for MT (Raiguel et al., 1989, 1999; Lagae et al., 1993; Schmolesky et al., 1998; Raiguel et al., 1989, 1999; Lisberger and Movshon, 1999) but was consistent with a report of responses from 30 to $40 \mathrm{msec}$ in area MST (Kawano et al., 1994). Overall, our mean onset latencies (Table 1) were smaller than most published mean values but were not inconsistent with published minimum latencies. This was expected for our rapidly changing stimulus because visual responses are known to be faster for rapid and broadband temporal stimuli (Shapley and Victor, 1978; Sestokas and Lehmkuhle, 1986; Movshon et al., 1990; Reid et al., 1992; Lagae et al., 1993; Kawano et al., 1994; Bair et al., 1997; Lisberger and Movshon, 1999).

Our offset latencies, being consistently smaller than onset latencies, were smaller than the minimum latency values reported in nearly all previous extracellular studies of these visual areas in the macaque monkey. Specifically, our earliest offset latencies were between 15 and $20 \mathrm{msec}$ in the LGN and between 20 and 25 msec in V1 and MT (Fig. 3, horizontal axis; see Table 1 for mean values). This is not inconsistent with physical limitations of the circuitry, and, given early responses in the LGN, is consistent with there being only several milliseconds of delay from LGN to cortex (Reid and Alonso, 1995, reported 1-4.5 msec for cat) and a 1-2 msec conduction delay from V1 to MT (Movshon and Newsome, 1996). Thus, offset latencies for our dynamic stimuli indicate that the flow of information through visual cortex can be faster than revealed by most extracellular studies of onset latency.

To quantify the difference between onset and offset latency for each cell, we defined $\Delta_{\mathrm{AP}}$ (Fig. $1 C$, thick bar) to be onset time minus offset time. Measurements of $\Delta_{\mathrm{AP}}$ across cell types and stimuli are summarized in Figure 4. For the LGN, in addition to the sinusoidal stimuli just described, cells were also tested with a constant-luminance disk in the center of the $\mathrm{RF}(A)$ and an

Table 1. Average response offset and onset latencies for the data plotted in Figure 3

\begin{tabular}{|c|c|c|c|c|c|c|}
\hline \multirow[b]{2}{*}{ Cell type } & \multirow[b]{2}{*}{ Stimulus } & \multicolumn{2}{|c|}{ Offset (msec) } & \multicolumn{2}{|c|}{ Onset (msec) } & \multirow[b]{2}{*}{$n$} \\
\hline & & Mean & $\mathrm{SD}$ & Mean & SD & \\
\hline LGN m-cell & Phase & 18 & 3.5 & 24 & 2.9 & 17 \\
\hline LGN p-cell & Phase & 27 & 12 & 37 & 14 & 14 \\
\hline V1 simple & Phase & 31 & 8.5 & 52 & 16 & 11 \\
\hline V1 simple & Orientation & 29 & 8.9 & 52 & 18 & 16 \\
\hline V1 complex DS & Direction & 28 & 6.6 & 38 & 6.1 & 34 \\
\hline MT & Direction & 29 & 5.2 & 40 & 4.8 & 39 \\
\hline
\end{tabular}


Figure 4. The distribution of the timing asymmetry, $\Delta_{\mathrm{AP}}$, across cell types and stimulus categories. $A$, LGN p-cells (gray bars, $n=13$ ) and m-cells (white bars, $n=12$ ) had $\Delta_{\mathrm{AP}}>0$ when driven by a disk in the RF center. The mean for p-cells, 8.9 msec (black arrow), was significantly greater than that for m-cells, $4.8 \mathrm{msec}$ (white arrow; $t$ test, $p=0.017$ ). $B$, When tested with an annulus in the RF surround, $\mathrm{p}$ - and m-cells had similar values of $\Delta_{\mathrm{AP}}$ (means, 7.8 and $7.2 \mathrm{msec}$, respectively). Arrows showing means overlap. $C$, For the phase stimulus, p-cells $(n=14)$ had a significantly larger $\Delta_{\mathrm{AP}}$ than m-cells $(n=17$; means, 10.1 and $6.5 \mathrm{msec} ; t$ test, $p=0.007)$. Black and white arrows show means for $\mathrm{p}$ - and m-cells, respectively. $D, \mathrm{~V} 1$ simple cells tested with the phase stimulus had more varied and larger $\Delta_{\mathrm{AP}}$ values on average (mean, $22 \mathrm{msec} ; n=12$ ) than $\Delta_{\mathrm{AP}}$ for the LGN. $E$, The distribution of $\Delta_{\mathrm{AP}}$ for V1 cells tested with the orientation stimulus was similar (mean, $22 \mathrm{msec} ; n=14$ ) to that for the phase stimulus. $F, \mathrm{~V} 1$ complex DS cells $(n=32)$ tested with the direction stimulus had on average a smaller $(9.5 \mathrm{msec})$ and less scattered value of $\Delta_{\mathrm{AP}}$ than simple cells tested with static gratings. $G$, MT cells $(n=$ 34) tested with the direction stimulus had a distribution of $\Delta_{\mathrm{AP}}$ similar to that for V1 complex DS cells (mean, 10.9 $\mathrm{msec})$.

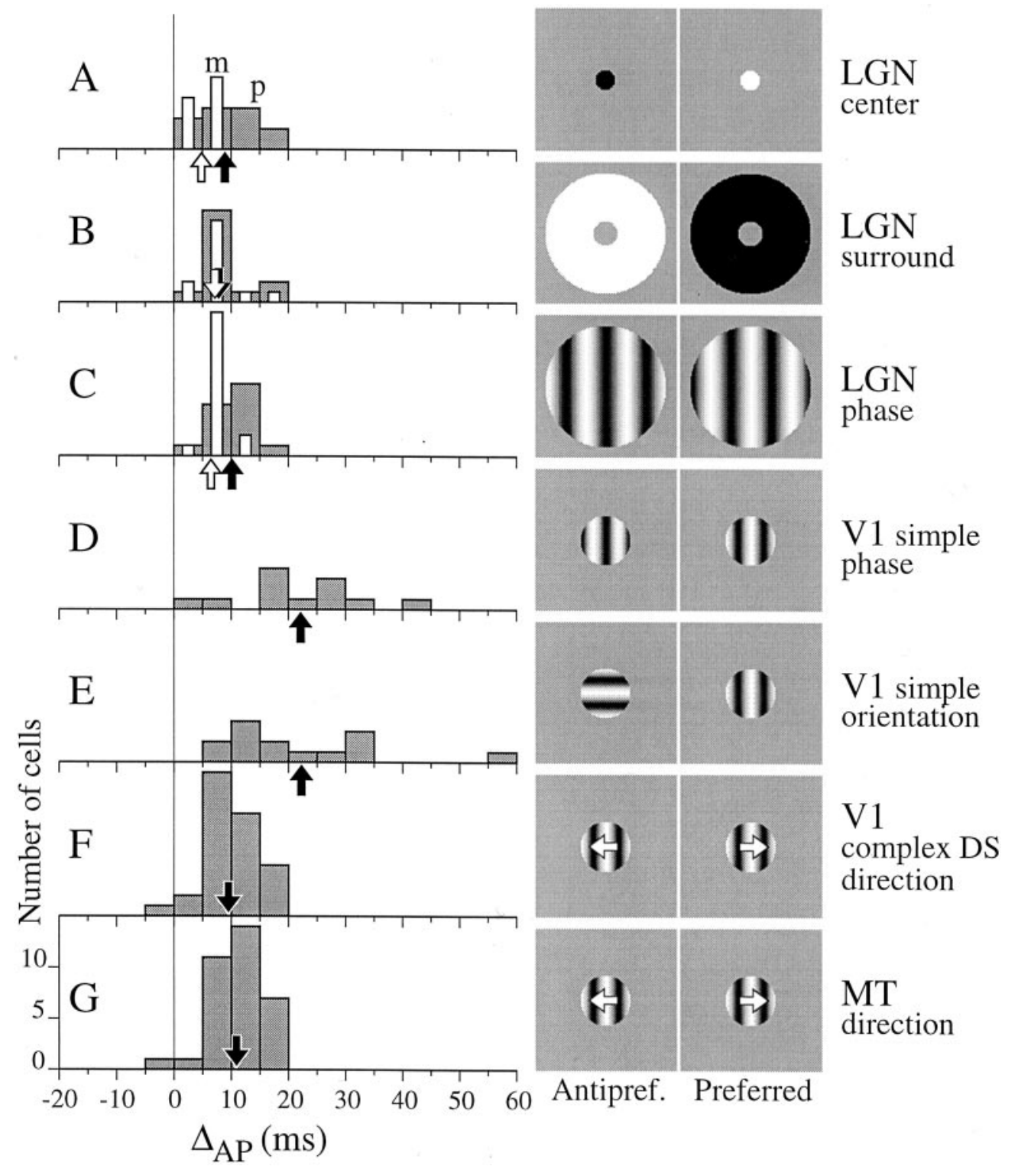

annulus that omitted the center $(B)$. The average value of $\Delta_{\mathrm{AP}}$ was significantly smaller for m-cells than for $\mathrm{p}$-cells when the stimulus was limited to the center of the RF (Fig. $4 A$, compare white with gray histograms; arrows show means; see legend for statistics). For surround stimulation, the distributions of $\Delta_{\mathrm{AP}}$ for $\mathrm{p}$ - and m-cells were statistically indistinguishable $(B)$. Results for the phase stimulus $(C)$ were well matched to those for the center disk. ON and OFF center LGN cells showed no differences in timing measurements and were grouped together. Compared with the LGN, V1 simple cells had larger and more varied values of $\Delta_{\mathrm{AP}}$. This was true for responses to the phase stimulus $(D)$ and the orientation stimulus $(E)$. Complex DS cells in V1 $(F)$, however, had an average $\Delta_{\mathrm{AP}}$ that was significantly less than that for simple cells and was more similar to the distribution for the LGN. The distribution of $\Delta_{\mathrm{AP}}$ for MT cells $(G)$ was similar to that for V1 complex DS cells.

Response latencies in V1 are known to be widely distributed, and Figure 4, $D$ and $E$, shows that $\Delta_{\mathrm{AP}}$ was widely distributed for V1 simple cells. Do cells with long latencies have large $\Delta_{\mathrm{AP}}$ ? For LGN p-cells and V1 simple cells, we found a positive correlation between $\Delta_{\mathrm{AP}}$ and onset latency $(r=0.70, p=0.006, n=14$ for LGN p-cells; $r=0.88, p=0.0004, n=11$ for V1 simple cells tested with the phase stimulus; $r=0.87, p=0.00001, n=16$ for simple cells tested with the orientation stimulus). There was a weak correlation between $\Delta_{\mathrm{AP}}$ and onset latency for area MT $(r=$ $0.36 ; p=0.02 ; n=39)$, but no significant correlation for LGN m-cells $(r=0.17 ; p=0.51 ; n=17)$ or for complex DS cells in V1 $(r=0.22 ; p=0.22 ; n=34)$. Thus, the correlation between $\Delta_{\mathrm{AP}}$ and onset latency was strongest for cell types that had the largest variations in onset latency, namely LGN p-cells and V1 simple cells. This is apparent in Figure 3, where the open and filled red circles and the filled black circles lie farther from the diagonal line at higher onset latencies.

In summary, for almost all of our cells, responses turned off faster than they turned on: only rarely was $\Delta_{\mathrm{AP}}$ less than zero. Cells with conspicuously long onset latencies tended to have large $\Delta_{\mathrm{AP}}$ values, suggesting that the time required to initiate a response can be substantially longer than the time required to decrease, or maintain, an ongoing response.

Eleven non-DS complex cells were tested with the orientation 


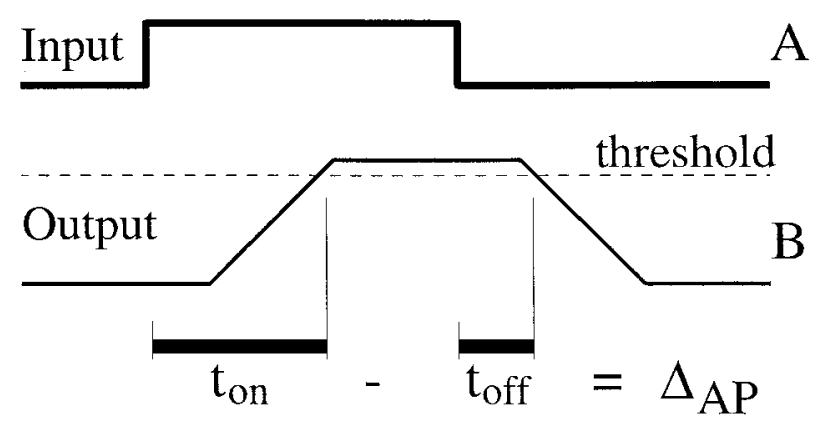

Figure 5. A system with a high threshold takes longer to turn on than to turn off. If the input in $A$, plotted as a function of time, is delayed and smoothed by convolution with a boxcar function, the trace in $B$ results. The delay from the rise in the input to the rise in the output is equal to that from the fall in the input to the fall in the output. However, if the system responds only when the output is above a high threshold (dashed line), the latency to response onset $\left(t_{\text {on }}\right)$ is longer than the latency to offset $\left(t_{\text {off }}\right)$ by an amount approximately equal to the time to rise to threshold. Thus, $\Delta_{\mathrm{AP}}$ approximates the integration time of the system in this simple demonstration.

stimulus, but none responded to the fast changes between preferred and antipreferred stimuli in a manner similar to that of the other cell types. In particular, their firing rates decreased for both PA and AP transitions. Results for these cells cannot be compared directly to those presented here; therefore, complex non-DS cells are not included in our analysis.

\section{The relationship between $\Delta_{\mathrm{AP}}$ and firing rate}

A linear system would not have a latency asymmetry, $\Delta_{\mathrm{AP}}>0$, as observed in our data, but an otherwise linear system with a high threshold for response could. This is depicted in Figure 5, which shows an input $(A)$ that is convolved with a rectangular pulse (data not shown) to yield an output $(B)$ that is thresholded. The threshold (dashed line) is set high, so the onset latency, $t_{\mathrm{on}}$, is longer than the offset latency, $t_{\mathrm{off}}$, and $\Delta_{\mathrm{AP}}>0$. The spontaneous firing rate of a neuron is a potential indication of the height of the threshold of the "system" that drives the output of that neuron, with a low spontaneous rate indicating a high threshold. We therefore tested for a correlation between $\Delta_{\mathrm{AP}}$ and the spontaneous firing rate, which we computed during the $500 \mathrm{msec}$ epoch that preceded stimulus onset.

A plot of $\Delta_{\mathrm{AP}}$ against spontaneous rate for five classes of neurons (Fig. 6A) shows that cells with lower spontaneous rates tended to have larger $\Delta_{\mathrm{AP}}$ values. This was clearest in the LGN, where spontaneous rates were higher and more varied than in cortex. The histograms in Figure $6 B$ show the distributions of spontaneous rates in LGN, in V1 for simple and complex DS cells, and in MT. It is well established that spontaneous rate decreases from retina to LGN to cortex (Herz et al., 1964). Because of the low spontaneous firing rates in V1, we were not surprised to find a lack of correlation between $\Delta_{\mathrm{AP}}$ and spontaneous rate. However, as a population, V1 simple cells were consistent with the trend for LGN cells, they typically had lower firing rates and higher $\Delta_{\mathrm{AP}}$ values than LGN cells (compare red circles with filled and open circles in Fig. 6A). V1 complex DS cells also alone showed no significant correlation between spontaneous rate and $\Delta_{\mathrm{AP}}$, but in MT, where spontaneous rates were moderately higher (Fig. $6 B$, bottom), there was a significant correlation between $\Delta_{\mathrm{AP}}$ and spontaneous rate. Correlation coefficients are shown by black bars in the left column of Figure $6 C$ (see legend for statistical significance). We also computed the correlation between $\Delta_{\mathrm{AP}}$ and stimulus evoked firing rate, which was measured in the $20 \mathrm{msec}$ epoch after the onset of response to an AP transition. The correlation coefficients for the evoked rate, shown in the righthand column of Figure $6 C$, were significantly negative for LGN P-cells, V1 simple cells, and MT cells, again showing that lower firing rates were associated with larger $\Delta_{\mathrm{AP}}$ values.

The association of low firing rate with large $\Delta_{\mathrm{AP}}$ is intuitively appealing because a mechanism that acts to pull a cell farther from threshold, e.g., by reducing its average resting potential, would not only decreases the firing rate but also could delay response onset and advance response offset, thereby increasing $\Delta_{\mathrm{AP}}$. Spontaneous firing rate reflects a steady-state condition of a cell, but antipreferred stimuli can momentarily suppress the spontaneous discharge and could, in effect, increase the distance to threshold. Therefore, we will now test whether $\Delta_{\mathrm{AP}}$ depended on the antipreferred stimulus.

\section{Assessing the influence of the antipreferred stimulus}

To test the hypothesis that the antipreferred stimulus contributed to the delay of response onset, we compared responses to AP transitions with those to null-to-preferred (NP) transitions. The $\mathrm{N}$ was either a mean gray field or, for DS cells, a static grating, and $\mathrm{N}$ can be thought of as a candidate neutral stimulus for the cell being tested. Each cell was tested with a random, ternary sequence in which $\mathrm{A}, \mathrm{N}$, or $\mathrm{P}$ was presented with equal probability every $10 \mathrm{msec}$. Average responses and response difference traces were computed for the NP and PN transitions by the same methods used for AP and PA transitions, with $\mathrm{N}$ taking the place of A.

Figure $7 A-F$ shows results for the cell types and stimuli that were examined previously in Figure 2. Each panel shows the familiar AP and PA response difference traces and the new NP and $\mathrm{PN}$ traces. In Figure $7 C$, where the traces are labeled, the firing rate of a V1 simple cell decreased for transitions from the preferred stimulus to the antipreferred (PA) (downward deflected black line) and to the null stimulus (PN) (downward deflected gray line). The response decrease began at about the same time regardless of whether $\mathrm{A}$ or $\mathrm{N}$ was the final stimulus. However, the timing of rate increases caused by transitions to the preferred stimulus depended on whether the initial stimulus was $\mathrm{N}$ or $\mathrm{A}$ : the responses to the NP transition (thick gray line) occurred sooner than the response to the AP transition (thin black line). All six examples in Figure 7 showed qualitatively similar behavior. The onset latency after antipreferred stimuli was longer than that after null stimuli, whereas the offset latency (after preferred) was approximately the same for PA and PN transitions. The latter observation is consistent with the idea that offset latency is determined by the loss of excitation (or activation of inhibition) caused by removal of the preferred stimulus. If A has a stronger influence than $\mathrm{N}$, it does not act rapidly enough to advance the timing of the initial decline in firing rate when $\mathrm{P}$ is removed.

We compared the onset timing for NP transitions to AP transitions quantitatively using $\Delta_{\mathrm{NP}}$ and $\Delta_{\mathrm{AP}}$, which are schematized on the right of Figure $7 G$. Both measurements were made relative to the offset time (arrow) determined from the PA transition (see Materials and Methods). As defined earlier, $\Delta_{\mathrm{AP}}$ is the onset time for the AP response minus the offset time, whereas $\Delta_{\mathrm{NP}}$ is the onset time for the NP response minus the offset time. The markings in the schematic in $G$ are similar to those used for the neuronal data in panel $C$ (horizontal brackets show timing measurements). If $\mathrm{N}$ and $\mathrm{A}$ stimuli had equivalent effects on 


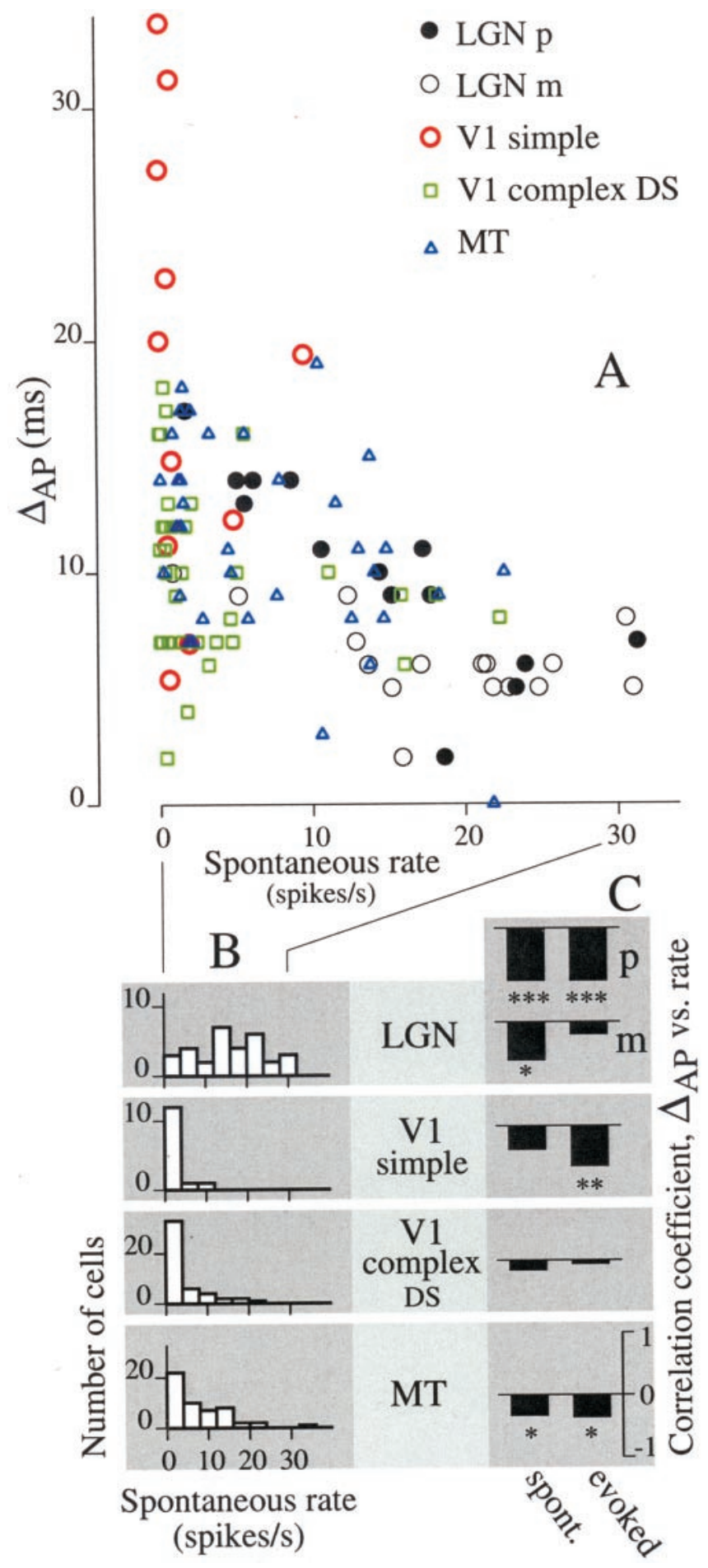

Figure 6. Firing rate is negatively correlated with $\Delta_{\mathrm{AP}}$. $A$, For five classes of neurons, $\Delta_{\mathrm{AP}}$ is plotted as a function of spontaneous rate. LGN p- and m-cells and V1 simple cells were tested with the phase stimulus. V1 complex DS and MT cells were tested with the direction stimulus. $B$, The distribution of spontaneous rate varies across cell class. LGN p- and $\mathrm{m}$-cell data were combined into one histogram because their distributions were statistically indistinguishable $(t$ test for mean, $p=0.34 ; F$ test for variance, $p=0.89$ ). LGN cells had high and varied spontaneous rates compared with cortical cells. $C$, Correlation coefficients computed between $\Delta_{\mathrm{AP}}$ and spontaneous rate (left column of bars) and between $\Delta_{\mathrm{AP}}$ and evoked rate (right column) were always negative. Asterisks indicate statistical significance: ${ }^{*} p<0.05 ; * * p<0.01 ; * * p<0.001$. Evoked firing rate was computed in the $20 \mathrm{msec}$ period after the onset of response to the AP transition. response timing, then $\Delta_{\mathrm{NP}}=\Delta_{\mathrm{AP}}$. If the null stimulus caused no delay in response onset relative to offset, then $\Delta_{\mathrm{NP}}=0$.

A cell-by-cell comparison of $\Delta_{\mathrm{NP}}$ and $\Delta_{\mathrm{AP}}$ is provided by the scatterplot in Figure $7 G$. For all cells, $\Delta_{\mathrm{NP}}<\Delta_{\mathrm{AP}}$, and $\Delta_{\mathrm{NP}}$ was near zero for many cells that had small $\Delta_{\mathrm{AP}}$ (approximately $\Delta_{\mathrm{AP}}<10 \mathrm{msec}$ ). For each cell, we computed the ratio $\Delta_{\mathrm{NP}}: \Delta_{\mathrm{AP}}$ to asses the fraction of the delay, $\Delta_{\mathrm{AP}}$, that was present for the NP transition. We reasoned that a ratio measure would be justified if, as Figure $5 B$ implies, $\Delta_{\mathrm{AP}}$ primarily represents a neuronal integration time (as defined in Nowak and Bullier, 1997) and cannot be negative. Thus, if $\Delta_{\mathrm{AP}}$ is small because a cell has an intrinsically short integration time, even a large effect of the null stimulus cannot cause a large absolute decrease in the already short integration time. The distributions of the ratio for all cell types fell mainly between 0 and 1 , consistent with the scatter of points in $G$. Interestingly, for V1 simple cells, the ratio was significantly larger for the orientation stimulus (mean 0.71 , SD $0.12, n=5$ ) than it was for the phase stimulus (mean 0.31, SD 0.14, $n=4$; $t$ test, $p=$ 0.005). Taking the logarithm of the ratio, or using the absolute timing difference (because ratio measures are sensitive to noise in the denominator), did not destroy the significance of this result. This suggests that an orthogonal grating is more akin to mean gray than is a counterphase grating, and that the counterphase grating is the more appropriate antipreferred stimulus for V1 simple cells. It would be premature to draw any firm conclusion based on the low number of cells, but if this difference holds up, it provides quantitative evidence that afferent inhibition, associated with push-pull circuits (Ferster and Miller, 2000), is stronger than the recurrent inhibition associated with normalization and believed to underlie cross-orientation inhibition (Carandini et al., 1997).

We have just observed that responses to preferred stimuli were delayed more by $\mathrm{A}$ than by $\mathrm{N}$ stimuli, and we also observed that firing rate was related to response timing (Fig. 6). We will now examine the relationship between firing rate and delay for $\mathrm{N}$ and A stimuli. The mean firing rate in response to $\mathrm{NP}$ and $\mathrm{AP}$ transitions is plotted as a function of time in Figure $8 A$ for a V1 complex DS cell. The firing rate just before the response to the AP transition (black lines below arrow) was lower than the rate just before the response to the NP transition (gray lines below arrow). This was typical across cell types, but a few counterexamples were present. Figure $8 B$ shows a counterexample for which the firing rate just before the response to the AP transition was higher on average than the rate for the NP transition, yet the NP response still occurred sooner. For each cell, we computed the firing rates in the $10 \mathrm{msec}$ period before the onset of response to the NP and AP transitions and subtracted the rate for the AP case from the rate for the NP case. Figure $8 C$ shows the ratio of the timing measures, $\Delta_{\mathrm{NP}}: \Delta_{\mathrm{AP}}$, plotted against the firing rate difference (N-A) for cells marked by class and stimulus (for symbol legend, see Fig. $7 G$ ). There was a weak but significant correlation $(r=-0.43)$ between these measures across all cells and a significant correlation for MT cells alone (blue triangles, $r=$ -0.66; see legend for statistics). Points for the LGN (black circles) and V1 simple cells (red circles) contributed to the overall trend, whereas V1 complex DS cells (green squares) did not appear to follow the trend.

In summary, for the ternary sequences, antipreferred stimuli suppressed firing rate and delayed the onset of firing more than did null stimuli that were randomly interleaved with them. There was a mild tendency for cells with larger differences in firing rate to have larger timing differences in response to $\mathrm{N}$ and $\mathrm{A}$ stimuli by 

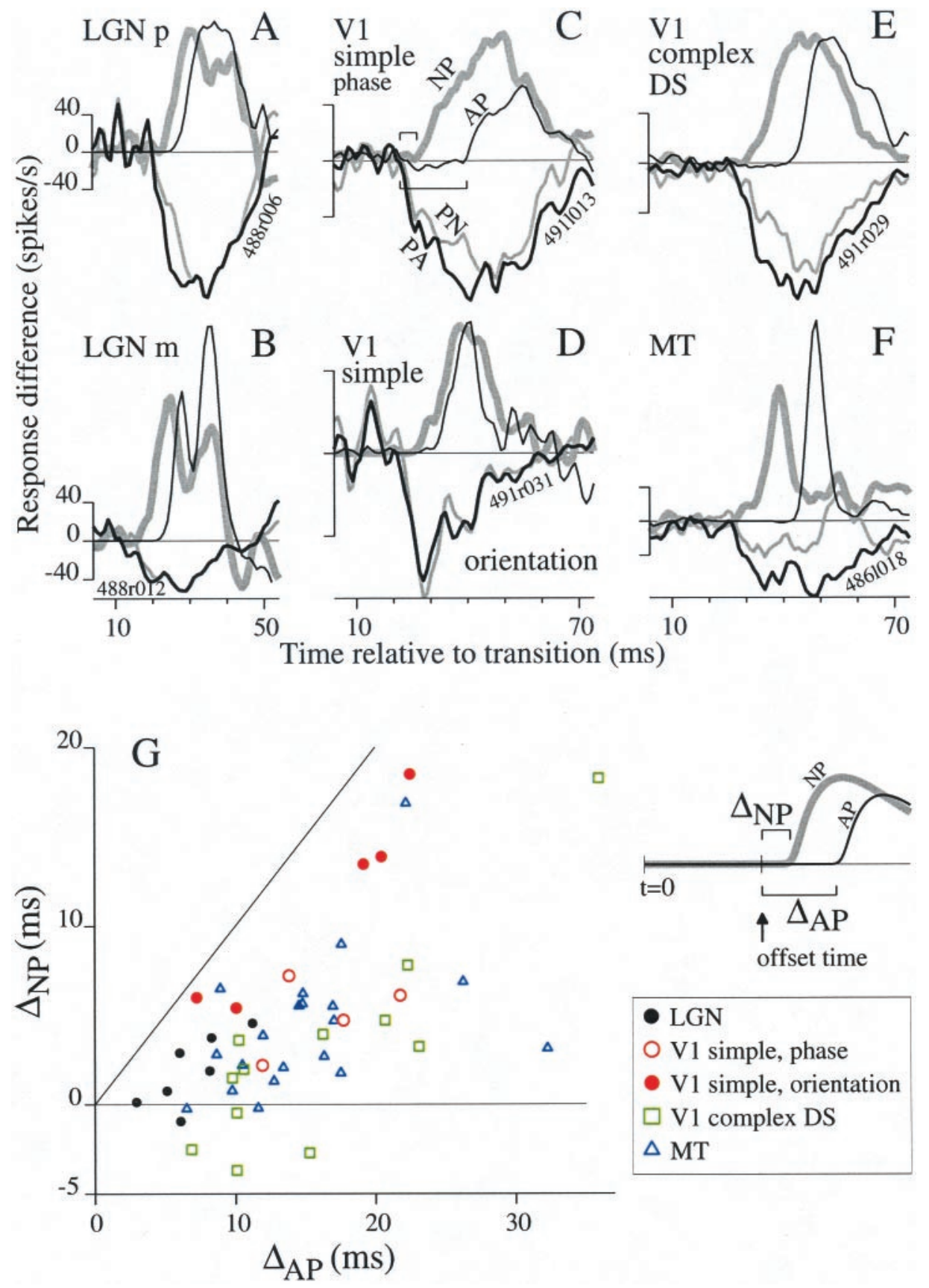

Figure 7. The response to a preferred stimulus is delayed more when it follows an antipreferred stimulus than when it follows a null stimulus. $A-F$, For six example cells, black lines show response difference traces for PA and AP transitions (medium and thin lines, respectively), and gray lines show response differences for PN and NP transitions (medium and thick lines, respectively). Cell types (top left corners) and stimulus categories match those in Figure 2. The phase stimulus applies to $A-C$, the orientation stimulus to $D$, and the direction stimulus to $E$ and $F$. Bars in $C$ indicate the latency of the NP ( graybar) and AP (open bar) responses relative to the PA latency. $G$, For all cells tested with ternary stimuli, $\Delta_{\mathrm{NP}}$ is plotted against $\Delta_{\mathrm{AP}}$. For all cells, $\Delta_{\mathrm{NP}}<\Delta_{\mathrm{AP}}$. When $\Delta_{\mathrm{AP}}$ was low, $\Delta_{\mathrm{NP}}$ was on average near zero. $\mathrm{m}$-Cells and p-cells were grouped together ( filled black circles) because there was no significant difference between their measurements plotted here (5 p-cells, 2 m-cells). our ratio measure. It is unlikely that the change in firing rate caused the change in timing, because if this were so, the scatter of points in Figure $8 C$ should go through unity for a rate difference of zero, but it did not. These results suggest that the antipreferred stimulus, and not just the lack of the preferred stimulus, contributed to the delay and that the magnitude of the delay may provide information beyond that carried by spike rate to distinguish the effects of various antipreferred and null stimuli.

\section{How the AP delay depends on antipreferred duration}

We have seen that the response to the onset of a preferred stimulus was delayed when that onset followed an antipreferred stimulus that was at least $30 \mathrm{msec}$ in duration. If the response was delayed because of suppression caused by the antipreferred pulse, then changing the duration of the antipreferred pulse might reveal the time course of the suppressive signal. Two scenarios are schematized in Figure 9, where panel $A$ shows four stimulus sequences with antipreferred pulses (plotted downward) of various lengths. Panel $B$ shows the time course of a hypothetical suppressive signal that simply integrates over the epoch of the A pulse. Traces are aligned to the AP stimulus transition (open arrow), so the longest duration A pulse (thick line in $A$ ) has created the strongest suppression (thick line in $B$ ) when the stimulus is about to change back to preferred. Alternatively, if a transient suppressive signal was associated with the onset of the antipreferred stimulus, a longer antipreferred epoch would result in weaker suppression (Fig. 9C, thick line), and a shorter A epoch could cause stronger suppression (thin lines in $A$ and $C$ ). We examined the time course of suppression by measuring responses 

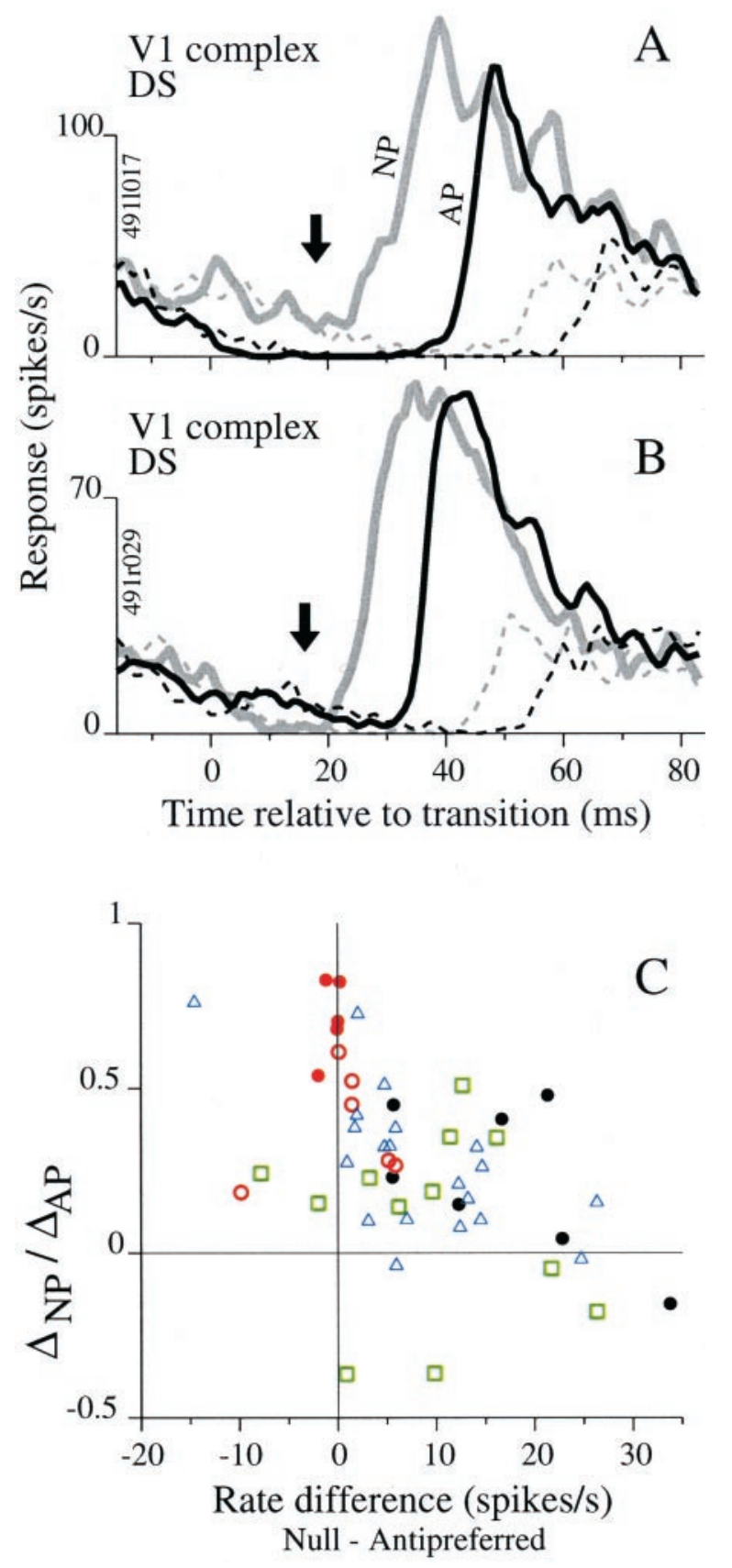

Figure 8. Comparing firing rates for antipreferred and null stimuli. $A$, Average responses for AP (black line) and NP (gray line) transitions and for reference stimuli (dashed lines of corresponding color; see Fig. $1 A$ for stimulus timing). Before the response to the preferred stimulus, the rate associated with $\mathrm{N}$ (gray lines below arrow) is higher than that associated with A (black lines below arrow). This trend held for 31 of 34 cells tested with the ternary, direction stimulus. Responses include at least 225 occurrences of each pattern. $B$, Format like $A$, but for one of three DS cells that had a higher firing rate before the AP response transition (black lines) than before the NP transition (gray lines). Responses include at least 450 occurrences of each pattern. $C$, The ratio $\Delta_{\mathrm{NP}}: \Delta_{\mathrm{AP}}$ is plotted against the difference between null and antipreferred firing rates (calculated in the $10 \mathrm{msec}$ epoch before the response to the transition) for LGN ( filled circles), V1 simple cells (red circles) tested with phase (filled) and orientation (open) stimuli, V1 complex DS cells (green squares), and MT cells (blue triangles). There was a significant correlation across the combined data sets $(r=-0.49$; $p=0.0003 ; n=50)$ and for the MT cells alone $(r=-66 ; p=0.001$; $n=20)$. None of the V1 data sets had significant correlations by themselves. For the LGN, $r=-0.60(p=0.15 ; n=7)$.

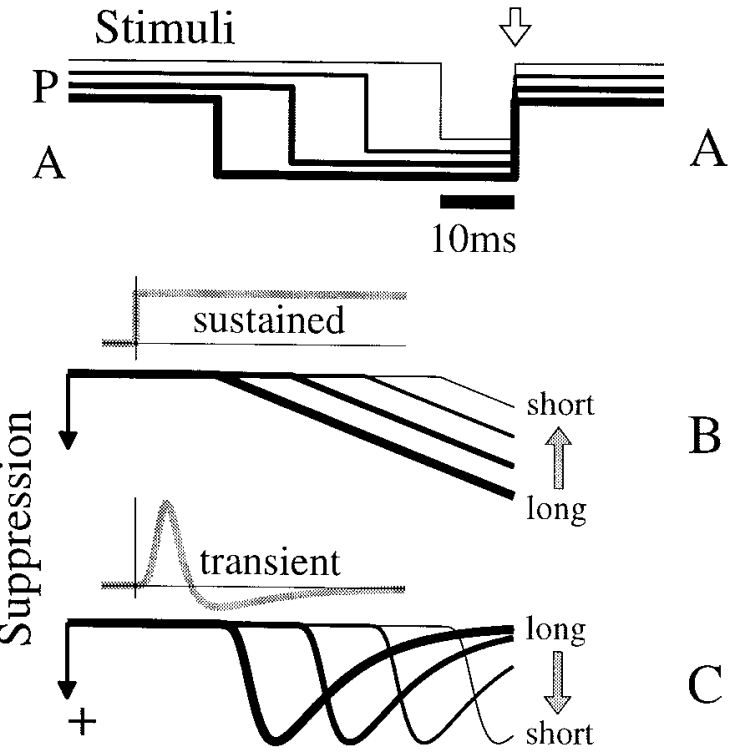

Figure 9. Two conceptual models of suppression activated during an antipreferred pulse make opposite predictions. $A$, Four stimulus sequences with various duration A pulses are aligned to the AP transition (open arrow). Thicker traces show stimuli with longer A pulses. Stimulus traces are offset vertically for clarity here, but traces in $B$ and $C$ have no vertical offset. $B$, The time course of suppression that resulted from a sustained integration of the A pulses is plotted with lines of the same thickness used for the stimuli in $A$. The stimuli were convolved with the gray step function, which models suppression that accumulates over time. The suppression was larger for longer A pulses (downward indicates stronger suppression). $C$, When the stimuli were convolved with a fast, transient function (gray line), suppression for longer A pulses had decayed more than that for shorter pulses at the time of the AP transition (right ends of lines). This trend is opposite to that in $B$.

that followed antipreferred epochs of various lengths. In our stimulus, the number of times that a sequence occurred declined exponentially with length; therefore, we limited our analysis to relatively short sequences for which timing could be measured accurately.

A series of $60 \mathrm{msec}$ stimulus sequences is plotted in Figure 10 ( $B$, gray inset). The first sequence (thickest line) consists of an antipreferred epoch of duration $T_{\mathrm{A}}=40 \mathrm{msec}$ followed by a preferred epoch of $20 \mathrm{msec}$. Successively thinner lines indicate stimuli with successively shorter antipreferred epochs, i.e., smaller values of $T_{\mathrm{A}}$. The dashed line is the reference stimulus, which has no antipreferred pulse. For these sequences, responses of an LGN p-cell to the phase stimulus are plotted versus time, relative to the AP transition, in Figure $10 A$ (time scale differs from stimulus inset). The response traces dropped from the reference response (dashed line) at times that reflected the onsets of the antipreferred pulses, but unlike the stimulus traces in the inset, the responses did not rise at the same time. As $T_{\mathrm{A}}$ became shorter, the response to the AP transition occurred later, i.e., the thinner lines rise later, as indicated by the gray arrow. Thus, short, i.e., recently applied, A pulses were the most effective for delaying response onset in the LGN, consistent with transient suppression schematized in Figure $9 C$.

Some V1 simple cells tested with the phase stimulus behaved like the example LGN cell just described, whereas others showed a second trend that is depicted in Figure 10B. For this cell, responses to the AP transition occurred earlier for sequences with shorter epochs of antipreferred stimuli (Fig. 10B, gray arrow). 

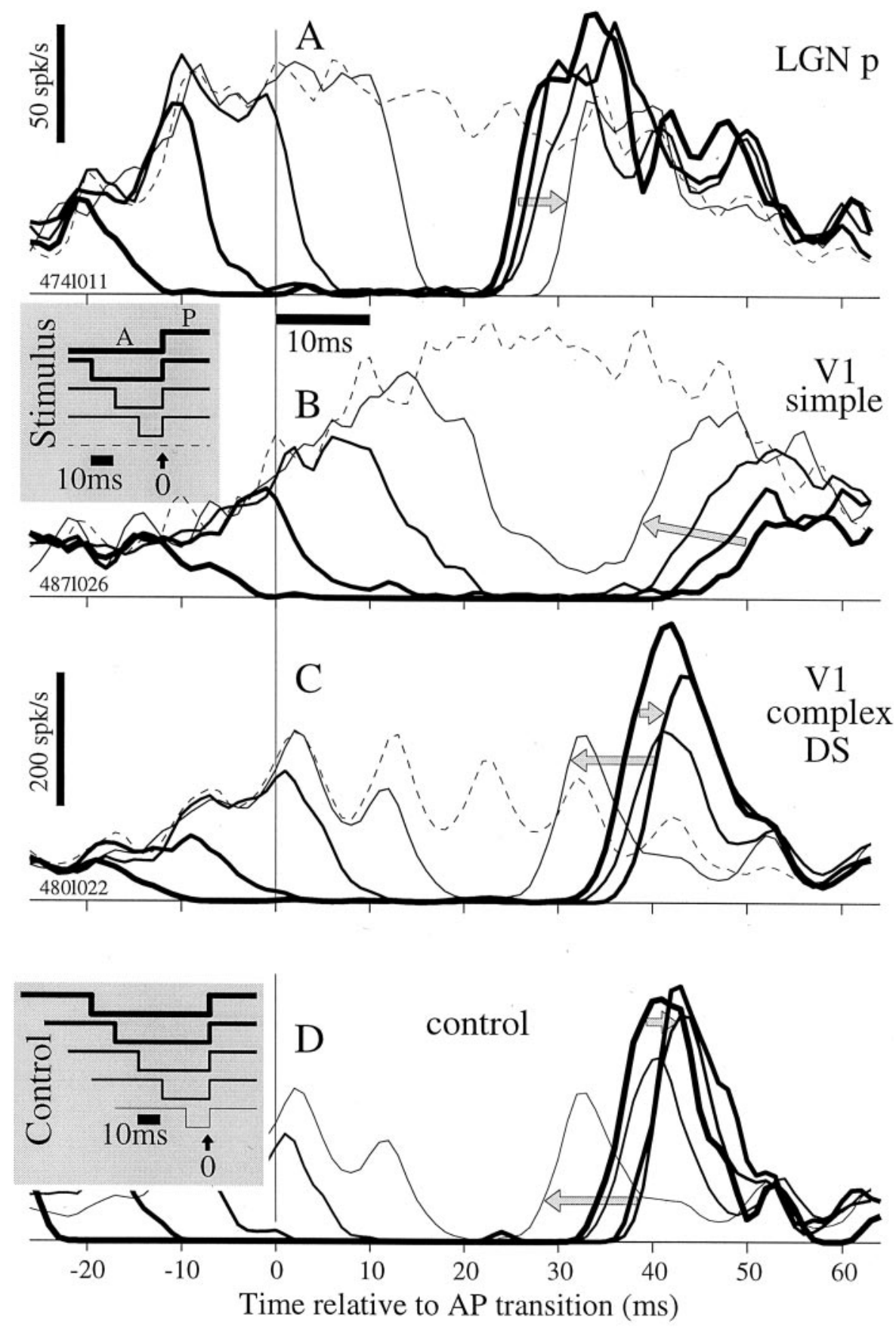

Figure 10. Latency depends on the duration of the antipreferred stimulus, and the dependency shows several trends across cell classes. $A$, LGN p-cell average responses for five stimulus sequences (see stimulus inset below $A$ ) for counterphase stimulus. The response delay increased (gray arrow) as the antipreferred epoch was shortened. This trend occurred for all p- and m-cells. Responses include at least 250 occurrences for each pattern. $B$, Responses for this V1 simple cell to the counterphase stimulus showed a trend opposite to that for LGN: the response delay decreased (gray arrow) as the antipreferred epoch was shortened. This was representative of more than half of V1 cells, whereas others showed a trend similar to that in the LGN. Responses include at least 250 occurrences for each pattern. $C$, Responses for a V1 complex DS cell to the direction stimulus show a third trend: response latency first increased (shorter arrow) and then decreased as the antipreferred epoch was shortened (longer arrow). Responses include at least 188 occurrences for each pattern. This was typical of V1 complex DS cells and MT cells. $D$, Responses are shown for six stimuli (gray inset), which each have $30 \mathrm{msec}$ of $\mathrm{P}$ before the A epoch. The fifth stimulus (thinnest line) is unchanged from the top panels. As $\mathrm{T}_{\mathrm{A}}$ shortens, the response to the AP transition first shifts rightward and then leftward, consistent with the behavior in $C$. Responses include 12, 24, 48, 94, and 192 occurrences for the thickest to thinnest lines, respectively.
This trend is consistent with suppression that accumulates over the time scale tested, as depicted in Figure 9B. We observed similar results for $20 \mathrm{~V} 1$ cells tested with the orientation stimulus. Cells tested with both stimuli behaved similarly, i.e., onset time either increased as in $A$ or decreased as in $B$ for both.

We observed a third trend for DS cells tested with the direction stimulus in V1 and MT. This is exemplified by data from a V1 complex DS cell in Figure $10 C$. As $T_{\mathrm{A}}$ decreased from 40 to 30 msec, the response latency increased (short gray arrow), but further reduction of $T_{\mathrm{A}}$ caused a decrease in latency (long gray arrow). The response for $T_{\mathrm{A}}=10 \mathrm{msec}$ was shifted abruptly to the left (thin line).

For each cell, we computed the onset latency of the average response for $T_{\mathrm{A}}=40 \mathrm{msec}$ and used this as a reference time.
Onset latencies for $T_{\mathrm{A}}=30,20$, and $10 \mathrm{msec}$ were expressed relative to the reference time. These data are plotted in Figure 11 for each cell that provided clear response onsets for all four $T_{\mathrm{A}}$ values. For the LGN, response latency increased at shorter $T_{\mathrm{A}}$ for almost every cell that we studied, and the increase was greater on average for m-cells (black lines) than for p-cells (Fig. 11A, gray lines) (see legend for statistics). The average change in onset latency for $\mathrm{m}$ - and p-cells is plotted in the inset at the bottom of $A$. For V1 simple cells tested with the phase stimulus, the results varied widely across cells (Fig. 11B). For shorter A pulses, onset latency increased for some cells but decreased for others. The thick line shows data for the example in Figure $10 \mathrm{~B}$. No average across cells is shown because it would not reflect the diversity found in V1 simple cells. Results for simple cells tested with the 
Figure 11. Summary of duration dependence of latency across cell classes. Relative latencies for 5\% rise-to-peak are plotted against the duration of the antipreferred stimulus, $\mathrm{T}_{\mathrm{A}}$, that preceded the AP transition. All values are given relative to the value for $\mathrm{T}_{\mathrm{A}}=40$ msec. $A$, Each line emanating from the point $(40,0)$ shows data for a p-cell (gray lines) or an m-cell (black lines). For nearly all LGN cells, latency increased as $\mathrm{T}_{\mathrm{A}}$ decreased. The average relative latencies are plotted for p-cells (gray line) and m-cells (black line) in the inset (error bars show \pm 1 SEM). m-cells on average had significantly longer relative latencies ( $t$ test; $p<0.00001 ; 7.0>3.7$ msec; $\left.\mathrm{T}_{\mathrm{A}}=10 \mathrm{msec}\right)$. Results shown here are for counterphase stimuli. Cell counts appear in parentheses. $B$, Similar data are plotted for V1 simple cells tested with counterphase stimuli. These plots show that V1 had more diverse behavior than the LGN. Latency could increase or decrease as $\mathrm{T}_{\mathrm{A}}$ decreased. The thick line corresponds to the example data in Figure $10 B$ for which the latency decreased with $\mathrm{T}_{\mathrm{A}}$. $C$, Similar to $B$, but for $\mathrm{V} 1$ simple cells tested with the

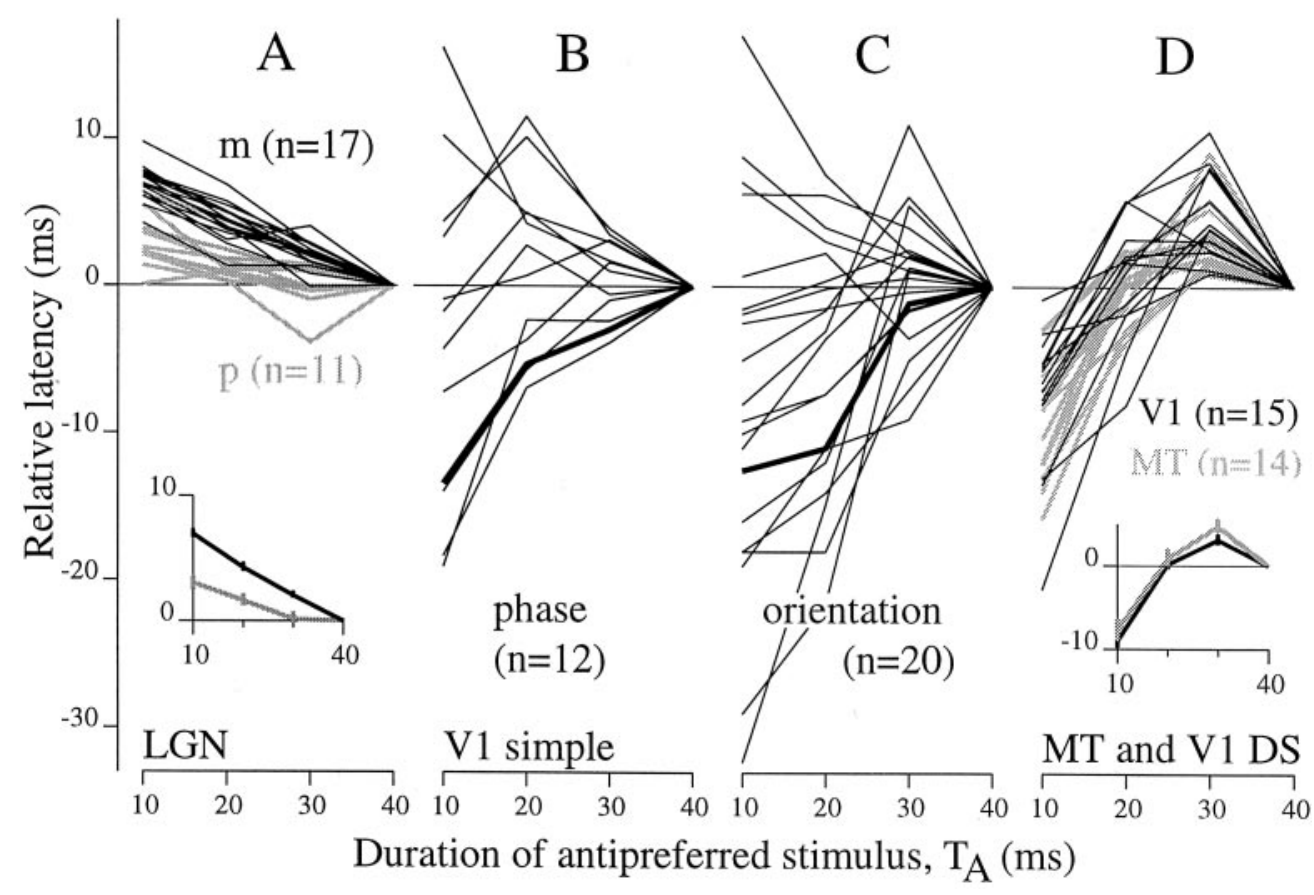

orthogonal orientation stimulus. The thick line here and in B show data collected from the same cell. D, For V1 complex cells (black lines) and MT cells (gray lines) tested with the direction stimulus, response latency first increased and then decreased as $\mathrm{T}_{\mathrm{A}}$ was reduced from 40 to $10 \mathrm{msec}$. The inset shows the average relative latency for MT cells and V1 complex DS cells.

orientation stimulus showed a similar diversity $(C)$. Complex DS cells in V1 and cells in MT that were tested with the direction stimulus showed behavior similar to each other (Fig. 11D) and were less diverse than V1 simple cells. There was an initial increase followed by a larger decrease in latency as $T_{\mathrm{A}}$ decreased from 40 to $10 \mathrm{msec}$. Average changes in latency are plotted in the inset in $D$. The data in Figure 11 show that the signals from preferred and antipreferred stimuli do not interact in the same way across cortical areas and cell types, at least at the time scale of tens of milliseconds.

The changes in onset latency with antipreferred pulse duration can be related back to our estimates of $\Delta_{\mathrm{AP}}$ reported in Figure 4. Those results were derived from responses to $50 \mathrm{msec}$ sequences beginning with $30 \mathrm{msec}$ of $\mathrm{A}$; therefore, they are most comparable with the results for $T_{\mathrm{A}}=30$ or $40 \mathrm{msec}$ here. For LGN cells, this implies that $\Delta_{\mathrm{AP}}$ for shorter (10-20 msec) antipreferred pulses would be on average larger than reported in Figure $4 C$. Interestingly, the larger increase in onset latency for m-cells compared with p-cells for short A pulses (Fig. 11 $A$ ) appears to compensate for the shorter $\Delta_{\mathrm{AP}}$ value for m-cells shown in Figure $4 C$. In fact, the average values of $\Delta_{\mathrm{AP}}$ computed using the onset time for the $T_{\mathrm{A}}=10 \mathrm{msec}$ responses were 12.5 and $12.3 \mathrm{msec}$ for $\mathrm{p}-$ and m-cells, respectively (SD 3.1, $n=11$ for p-cells, SD 3.0, $n=17$ for $\mathrm{m}$-cells). For V1 complex DS cells and MT cells, the change in onset latency from $T_{\mathrm{A}}=30-40 \mathrm{msec}$ to $T_{\mathrm{A}}=10 \mathrm{msec}$ was approximately $-10 \mathrm{msec}$ (Fig. $11 \mathrm{D}$ ), which is equal but opposite to the mean $\Delta_{\mathrm{AP}}$ reported in Figure $4 F$ and $G$. Thus, the early response onset after a $10 \mathrm{msec}$ pulse of antipreferred motion (Fig. $10 C$, thin solid line) occurs very close to the response offset time computed previously from the PA transition. On average $\Delta_{\mathrm{AP}}$ is only $\sim 3 \mathrm{msec}$ for $\mathrm{V} 1$ and MT when computed using the onset time for $T_{\mathrm{A}}=10 \mathrm{msec}$. This suggests that $10 \mathrm{msec}$ of motion reversal is too brief to activate the mechanism by which the antipreferred stimulus delays response onset.
Finally, for the stimulus sequences just examined, two factors were changing at once: the duration, $T_{\mathrm{A}}$, of $\mathrm{A}$ and the duration, $T_{\mathrm{P}}$, of $\mathrm{P}$ that preceded A. A set of control sequences in which $T_{\mathrm{P}}$ was held constant at $30 \mathrm{msec}$ are shown in the gray inset in Figure $10 D$. The rightward and then leftward shift in the latency of the AP responses to these stimuli (Fig. 10D, gray arrows) was similar to that observed in $C$. The longest stimulus sequence $(100 \mathrm{msec})$ occurred only 12 times. The infrequent occurrence of the longer sequences made them less useful than the constant length sequences (Fig. 10, top inset) for accurate estimation of response trends. Nevertheless, the shifts in latency for the longer sequences were qualitatively similar to those for the shorter sequences for the cell types described here. This is not to say that the sequence before the antipreferred pulses had no significant effect on responses. The sequence history affected the responses, but a full account of this is not attempted here. We simply demonstrate that onset latency showed history dependence that characterized and differentiated between cell classes.

\section{DISCUSSION}

We found that nearly all neurons in the LGN, V1, and MT responded more rapidly to a stimulus transition from preferred to antipreferred than to the opposite transition. The generality of this observation might be questioned because our rapidly changing stimulus differs from commonly used stimuli that flash on for $\sim 1$ sec after several seconds of homogeneous background. Published data for standard stimuli, however, suggest that $\Delta_{\mathrm{AP}}$ is positive for cat cortical neurons (von Baumgarten and Jung, 1952, their Fig. 3) and ranges from 3-9 msec for cat LGN cells (Coenen et al., 1972, their Table 1; Mastronarde, 1987a, his Table 1; Humphrey and Weller, 1988; Saul and Humphrey, 1990). Data of Adrian and Matthews (1927, their Fig. 5) and of Hartline (1938) suggest that $\Delta_{\mathrm{AP}}$ is positive in the early visual systems of other vertebrates as well. 
The $\Delta_{\mathrm{AP}}$ delay is derived from latency measurements and is therefore expected to be stimulus dependent. Response latency varies with stimulus parameters in the retina (Kuffler, 1953; Levick, 1973), in the visual areas studied here in monkey (Gawne et al., 1996; Lisberger and Movshon, 1999; Raiguel et al., 1999), and in human visual cortex (Parker and Salzen, 1977; Jones and Keck, 1978). In a separate study, we used slow movement for DS cells and high spatial frequencies for LGN cells and observed that $\Delta_{\text {AP }}$ may increase by $\geq 10 \mathrm{msec}$ (our unpublished observations). Here, we have used optimal spatial frequencies, high temporal frequencies, and fast motion, which shorten neuronal integration time (Shapley and Victor, 1978; Sestokas and Lehmkuhle, 1986; Reid et al., 1992; Lisberger and Movshon, 1999), to allow comparison of the lower bounds for $\Delta_{\mathrm{AP}}$ across areas. A full account of the variation of $\Delta_{\mathrm{AP}}$ across multiple stimulus dimensions and multiple visual areas will be presented elsewhere.

The offset latencies that we found suggest that information from the photoreceptors can reach LGN within 15-20 msec and V1 and MT within 20-25 msec. We believe that the rapid, dynamic nature of our stimuli and the measurement of offset rather than onset latency was responsible for revealing these short latencies. Response decreases have been reported to have exceptionally short latencies in visual cortex (Bartlett and Doty, 1974, their Fig. 3).

\section{Spontaneous rate}

We found an inverse correlation between $\Delta_{\mathrm{AP}}$ and spontaneous rate both across and within areas. For example, V1 simple cells had lower spontaneous rates and larger $\Delta_{\mathrm{AP}}$ compared with LGN cells. Within the LGN and MT, cells with lower rates had higher $\Delta_{\mathrm{AP}}$ values on average. Evidence that such a relationship could depend on resting potential comes from adaptation studies in area 17. Adaptation decreases spontaneous rate (Vautin and Berkley, 1977), increases onset latency (Saul, 1995), and hyperpolarizes cells (Carandini and Ferster, 1997; Sanchez-Vives et al., 2000). Further evidence comes from Azouz and Gray (1999), who reported a weak anticorrelation between latency to first evoked spike and the membrane potential $\left(V_{\mathrm{m}}\right)$ before stimulus onset for single trial data. If part of the variation in $\Delta_{\mathrm{AP}}$ across cells reflects differences in $V_{\mathrm{m}}$ established before the stimulus begins, $\Delta_{\mathrm{AP}}$ might be a useful extracellular indicator of changes in neuronal state, e.g., hyperpolarization or synaptic gain, caused by adaptation or other contextual manipulations. $\Delta_{\mathrm{AP}}$ and onset latency are not equivalent in practice because, for example, stimulus contrast affects onset and offset latency, whereas adaptation affects only onset latency (Saul, 1995).

Several studies have shown that neurons with stronger inhibition or lower spontaneous rates have more specific trigger features, i.e., are more narrowly tuned (Pettigrew et al., 1968; Creutzfeldt and Sakmann, 1969; Snodderly and Gur, 1995; Carandini and Ferster, 2000). Similar observations were reported for the auditory nerve: cells with high intensity thresholds have less spontaneous activity (Kiang et al., 1965, 1976). We tested for a relationship between orientation tuning bandwidth and $\Delta_{\mathrm{AP}}$ and found weak correlations for V1 simple cells $(r=-0.46 ; p=0.02$; $n=27)$ and MT cells $(r=-0.32 ; p=0.05 ; n=34)$ but not for complex DS cells $(r=-0.17 ; p=0.33 ; n=34)$.

\section{A versus $\mathbf{N}$ stimuli}

Do antipreferred stimuli delay response onset? Lisberger and Movshon (1999) showed that brief pulses of antipreferred motion delayed responses in MT. Data from Celebrini et al. (1993, their
Figs. 8 and 9) showed the same effect for flashed orthogonal gratings in awake macaque V1. We found that, when tested together in ternary sequences, A caused longer delays than $\mathrm{N}$ in LGN, V1, and MT and that firing rate for most cells was lower for A than for $\mathrm{N}$ just before the transition to $\mathrm{P}$. There were exceptions, however, in which A produced a higher rate and a longer delay than N. In contrast, onset latency was never longer for NP than for AP transitions. Changes in timing and firing rate were only weakly correlated in our comparison of $\mathrm{A}$ and $\mathrm{N}$ stimuli across cells, and V1 simple cells showed no significant difference in firing rate but displayed significant timing differences. Therefore, differential effects on onset timing may provide useful information that is not available from firing rate for the quantitative evaluation and ranking of visual stimuli. To detect differences among candidate antipreferred and null stimuli, it might be critical to interleave them in rapid succession as we have done, because the visual system may adapt and conceal such differences if stimuli are displayed for a long time or are shown separately in a binary sequence that includes a potent preferred stimulus.

\section{The origin of $\Delta_{\mathrm{AP}}$}

We found similarities and significant differences in $\Delta_{\mathrm{AP}}$ across cell classes and will consider below how they might arise. Several factors probably contribute to $\Delta_{\mathrm{AP}}$. First, spiking neurons share properties with integrate-and-fire devices and, as evident from intracellular current injection, their rise times to threshold can range from $<1$ msec to many tens of milliseconds. Cessation of spiking, however, is nearly immediate when the input is removed. If the Output in Figure $5 B$ were interpreted as $V_{\mathrm{m}}$, it would imply that $\Delta_{\mathrm{AP}}$ was entirely neuronal integration time (the time from depolarization to spike, see Nowak and Bullier, 1997). As mentioned above, we have intentionally chosen stimulus parameters to minimize integration time. Second, because onset latency depended on the stimulus before the transition to preferred, perhaps inhibition driven by A delays the rise to threshold. Third, if signals are directly relayed by feedforward excitatory connections, $\Delta_{\mathrm{AP}}$ should accumulate downstream. Thus, part of $\Delta_{\mathrm{AP}}$ may be inherited from excitatory inputs.

\section{$\Delta_{\mathrm{AP}}$ in the LGN}

For $30 \mathrm{msec}$ antipreferred pulses, the average $\Delta_{\mathrm{AP}}$ for m-cells driven via their center was significantly smaller than that for any other class of cells that we studied. m-Cells might have faster integration times than p-cells $(5 \mathrm{msec}$ vs $\sim 10 \mathrm{msec}$ ) because of increased spatial convergence. Alternatively, achromatic stimuli may be suboptimal for p-cells, thereby increasing integration time. Both explanations are consistent with the lack of difference in $\Delta_{\mathrm{AP}}$ when $\mathrm{m}$ - and p-cells were driven via their surround, under the assumption that their surround mechanisms are more similar than their center mechanisms (Lennie et al., 1991; Lennie, 2000). Slower retinal axon conduction speed for p-cells (Mitzdorf and Singer, 1979) should not increase $\Delta_{\mathrm{AP}}$ because it would delay both onset and offset equally.

If LGN principle cells relay retinal spikes with near 1:1 transmission, as observed for some LGN X cells in cat (Cleland et al., 1971; Coenen and Vendrik, 1972; Mastronarde 1987b), then $\Delta_{\mathrm{AP}}$ is simply inherited from the retina because retinogeniculate transmission delay is negligible (Wang et al., 1985; Mastronarde, 1987b). However, transmission ratios are often substantially $<100 \%$, and cat studies indicate that facilitation of consecutive EPSPs occurs (Singer et al., 1970; Mastronarde, 1987b; Usrey et al., 1998) possibly through simple summation (McIlwain and 
Creutzfeldt, 1967). If the first retinal spike resulting from an AP transition failed but the subsequent ones were transmitted, or if the first spike was delayed (Kaplan et al., 1993), the LGN relay would increase $\Delta_{\mathrm{AP}}$. A transient hyperpolarization occurs at light-off in ON LGN cells and light-on in OFF cells (McIlwain and Creutzfeldt, 1967; Coenen and Vendrik, 1972), and this might contribute to the failure of the first spike, and might account for the longer delay for shorter antipreferred epochs that we have observed.

Overall, we speculate that part of $\Delta_{\mathrm{AP}}$ in the LGN is inherited from the retina, and the rest is caused by failure of the first EPSP to reach threshold because of a transient, fast-rising hyperpolarization (Coenen and Vendrik, 1972). Such a hyperpolarization could explain the observed increase in latency for shorter antipreferred pulses (schematized in Fig. 9C). There is evidence for inhibition in the geniculate (Singer and Creutzfeldt, 1970; Coenen and Vendrik, 1972; Sherman and Koch, 1986; Mastronarde 1987b), but significant opponent inhibition is absent because $\mathrm{ON}$ and OFF pathways remain separate through the geniculate (Casagrande and Norton, 1991; Schiller, 1992). This may account for $\Delta_{\mathrm{AP}}$ being much smaller in LGN than in V1 simple cells. Also, we predict that retinal ganglion cells, having higher spontaneous and driven firing rates than LGN cells, should have smaller $\Delta_{\mathrm{AP}}$ than LGN cells, in keeping with the observed anticorrelation between firing rate and $\Delta_{\mathrm{AP}}$.

\section{$\Delta_{\text {AP }}$ in V1 simple cells}

$\Delta_{\text {AP }}$ was significantly larger for simple cells than for other cell types. The mean value, $22 \mathrm{msec}$, was $12 \mathrm{msec}$ longer than that for p-cells responding to similar stimuli. Thus, $<50 \%$ of $\Delta_{\mathrm{AP}}$ in most simple cells could be inherited from the LGN. Spontaneous rate is low in simple cells relative to retinal and geniculate cells, but it is also low in complex DS cells, which had $\Delta_{\mathrm{AP}}$ values more similar to p-cells. Data from the cat indicates that the integration time for simple cells is $\leq 10 \mathrm{msec}$, on average. Volgushev et al. (1995) estimated the time from EPSP arrival to first spike in area 17 for flashed optimal bar stimuli to be $7.6 \mathrm{msec}$. Data of Hirsch et al. (1998) using less optimized stimuli also depict a fast rise in $V_{\mathrm{m}}$ before the first spike. This is supported by estimates of neuronal integration time from spike-triggered averages of $V_{\mathrm{m}}$ in vivo (Azouz and Gray, 1999) and in vitro (Nowak et al., 1997). Carandini et al. (1996) estimated integration time to range from $14 \mathrm{msec}$ for sinusoidal current injection to $3 \mathrm{msec}$ for broadband current injection. Furthermore, spike precision in striate and extrastriate areas is consistent with integration times of only a few milliseconds (Maunsell and Gibson, 1992; Bair and Koch, 1996; Marvšálek et al., 1997). It is therefore not possible to account for the large $\Delta_{\mathrm{AP}}$ values of many simple cells on the basis of a combination of the $\Delta_{\mathrm{AP}}$ from the geniculate and the neuronal integration time of the recorded cell.

Intracellular studies of cat simple cells have shown that hyperpolarization follows the removal of an excitatory stimulus (Creutzfeldt and Ito, 1968) and that this is likely to result from inhibition (Ferster, 1988; Borg-Graham et al., 1998; Hirsch et al., 1998; Ferster and Miller, 2000). When GABA-mediated inhibition on simple cells was blocked, strong transient responses appeared at the offset of the preferred stimulus (Sillito, 1975; Eysel et al., 1998), suggesting that potent inhibition normally occurs at this time. We therefore suspect that inhibition associated with the antipreferred stimulus delays the onset of the rise to threshold in simple cells. If so, there may be at least two mechanisms by which the inhibition arises to account for the variation of time depen- dence of the onset latency. An inhibition that adapts could account for cells that show increased delay for shorter A epochs, whereas an inhibition that integrates slowly could account for the increased delay for longer A epochs.

As mentioned above, it is possible that part of $\Delta_{\mathrm{AP}}$ is inherited from the LGN, but a push-pull arrangement of inputs could prevent this. For instance, when a spot of light turns off and then on in an ON region of a V1 simple RF, the simple cell waits 10 msec longer for signals from an ON p-cell than it does for the loss of signal from an OFF p-cell. Thus, the first signal to the simple cell could be the removal of inhibition that could initiate the integration to threshold without delay. For this to be practical, inhibitory neurons would have to be fast, which they are (Agmon and Connors, 1992; Swadlow, 1995; Tamás et al., 1997; Porter et al., 2001), and must integrate inputs from many cells, which appears likely (Freund et al., 1985; Swadlow, 1995), so that real OFF signals are not confounded with long interspike intervals (Levick, 1973). Thus, one advantage to receiving inhibitory and excitatory inputs to the same receptive field location might be to cancel the $\Delta_{\mathrm{AP}}$ timing asymmetry, which for suboptimal stimuli may be substantially longer than the 5-10 msec reported here.

\section{$\Delta_{\text {AP }}$ in DS cells}

The distributions of $\Delta_{\mathrm{AP}}$ for complex DS cells and MT cells were similar (means were 10 and $11 \mathrm{msec}$, respectively) and resembled those for the LGN more than those for simple cells. If $\Delta_{\mathrm{AP}}$ resulted purely from integration to threshold in the recorded cell, and if V1 cells drove MT cells in a direct manner (Movshon and Newsome, 1996), $\Delta_{\mathrm{AP}}$ would be larger in MT than in V1 and response onset would occur later in MT. Neither of these conditions held for our data: MT average onset and offset were $\sim 1-2$ msec longer than V1 (Table 1). One possibility is that $\Delta_{\mathrm{AP}}$ in MT is inherited completely from its V1 inputs. Rapid transmission time from V1 to MT (Movshon and Newsome, 1996) could explain why we observed no significant latency difference, and spatial convergence could account for an integration time in MT that was closer to one msec than ten. The large axon diameter from V1 to MT (Rockland, 1995) certainly suggests that rapid transmission is critical in this pathway. Alternatively, a push-pull circuit could account for the absence of increase in $\Delta_{\mathrm{AP}}$ from V1 to MT, allowing cells in both areas to have similar neuronal integration times.

For DS cells, we observed an interesting trend in onset latency as a function of antipreferred duration. As A duration decreased, a reversal in latency occurred: responses after $10 \mathrm{msec}$ of A came sooner than those after $40 \mathrm{msec}$ of A (Fig. 10C). Perhaps a transient suppression is activated (as depicted in Fig. 9C) for longer A pulses, but the $10 \mathrm{msec}$ pulse is simply not long enough to activate the suppressive mechanism (i.e., implying that the thinnest line in Fig. 9C would not make its downward deflection). If this trend is a signature of the interaction of opponent directional signals, it is surprising that it is similar in V1 and MT in light of evidence that opponency is stronger in MT than in V1 (Qian and Andersen, 1994; Heeger et al., 1999). We do not yet know the mechanisms behind this trend, or the trends for LGN and V1, but believe that studying them may reveal important differences in circuits and intrinsic neuronal properties across visual areas.

\section{Response offset: the first sign of change}

Response latency is usually calculated for increases in firing rate (Raiguel et al., 1989; Maunsell and Gibson, 1992; Nowak et al., 
1995; Nowak and Bullier, 1997; Schmolesky et al., 1998; Maunsell et al., 1999; Raiguel et al., 1999), but our results demonstrate advantages of measuring latency for rate decreases. Not only is offset latency generally shorter than onset latency, but it may also be less variable. For V1 simple cells, which had large $\Delta_{\mathrm{AP}}$, offset latency was significantly less variable across cells (SD $9 \mathrm{msec}$ compared with $18 \mathrm{msec}$, F test, $p=0.01, n=16$, orientation stimulus). Saul (1995) showed that onset timing in simple cells was affected by adaptation, whereas offset timing was not. There is also evidence that offset latency is more consistent than onset latency in the somatosensory system (Ahissar et al., 2000). In other experiments, we found that offset latency changed significantly more than onset latency in the LGN when spatial frequency was varied and in cortical DS cells when stimulus velocity was varied. Together, these observations indicate that offset latency is less malleable, it lacks much of the dependency that onset latency has on the previous state of the cell and network, and could provide a reliable estimate of the minimal latency from a change in the peripheral stimulus to a change in output of the recorded cell. The use of response onset, which varies greatly with stimulus parameters and the previous state of the neuron, may be partly responsible for large discrepancies between latency measurements in V1 (for review, see Nowak and Bullier, 1997). For very transient responses, however, offset latency may be difficult to measure. Alternatively, latency to an increase in an already suprathreshold response should have similar properties to offset latency.

Offset latency may be more than just a useful tool for studying visual processing. The earliest cortical signals to indicate a change in the visual scene will arise in neurons that lose their preferred stimulus when the scene changes. Therefore, we propose that the offset of the responses of strongly driven cells to the previous scene acts as a reference signal for the visual system to interpret the waves of action potentials that follow a sudden scene change. The change may be induced by a sudden change in the environment or an eye movement. Response onset is known to carry information about stimulus features in vision (Gawne et al., 1996) and audition (Middlebrooks et al., 1994), and making use of this information is aided by a temporal reference (Hopfield, 1995; Gautrais and Thorpe, 1998).

\section{REFERENCES}

Adelson EH, Bergen JR (1985) Spatiotemporal energy models for the perception of motion. J Opt Soc Am A 2:284-299.

Adrian ED, Matthews R (1927) The action of light on the eye. Part I. The discharge of impulses in the optic never and its relation to the electric changes in the retina. J Physiol (Lond) 63:378-414.

Agmon A, Connors BW (1992) Correlation between intrinsic firing patterns and thalamocortical synaptic responses of neurons in mouse barrel cortex. J Neurosci 12:319-329.

Ahissar E, Sosnik R, Haidarliu S (2000) Transformation from temporal to rate coding in a somatosensory thalamocortical pathway. Nature 406:302-306.

Albright TD, Desimone R, Gross CG (1984) Columnar organization of directionally selective cells in visual area MT of the macaque. J Neurophysiol 51:16-31.

Azouz R, Gray CM (1999) Cellular mechanisms contributing to response variability of cortical neurons in vivo. J Neurosci 19:2209-2223.

Bair W, Koch C (1996) Temporal precision of spike trains in extrastriate cortex. Neural Comput 8:1185-1202.

Bair W, Cavanaugh JR, Movshon JA (1997) Reconstructing stimulus velocity from neuronal responses in area MT. In: Advances in neural information processing systems, Vol 9 (Mozer MC, Jordan MI, Petsche T, eds), pp 34-40. Cambridge, MA: MIT.

Bair W, Cavanaugh JR, Smith MA, Movshon JA (2001) Switching between off and on in the macaque visual system. Paper presented at the annual meeting of the Vision Sciences Society, Sarasota, FL, May.

Barlow HB (1953) Summation and inhibition in the frog's retina. J Physiol (Lond) 119:69-88.
Barlow HB, Hill RM (1963) Evidence for a physiological explanation of the waterfall phenomenon and figural after-effects. Nature 200:1345-1347. Bartlett JR, Doty RW (1974) Response of units in striate cortex of squirrel monkeys to visual and electrical stimuli. J Neurophysiol 37:621-641.

Benardete EA, Kaplan E (1997) The receptive field of the primate P retinal ganglion cell, I: linear dynamics. Vis Neurosci 14:169-185.

Benardete EA, Kaplan E (1999) The dynamics of primate M retinal ganglion cells. Vis Neurosci 16:355-368.

Benardete EA, Kaplan E, Knight BW (1992) Contrast gain control in the primate retina: $\mathrm{P}$ cells are not $\mathrm{X}$-like, some $\mathrm{M}$ cells are. Vis Neurosci 8:483-486.

Borg-Graham LJ, Monier C, Fregnac Y (1998) Visual input evokes transient and strong shunting inhibition in visual cortical neurons. Nature 393:369-373.

Carandini M, Ferster D (1997) A tonic hyperpolarization underlying contrast adaptation in cat visual cortex. Science 276:949-952.

Carandini M, Ferster D (2000) Membrane potential and firing rate in cat primary visual cortex. J Neurosci 20:470-484.

Carandini M, Mechler R, Leonard CS, Movshon JA (1996) Spike train encoding by regular-spiking cells of the visual cortex. J Neurophysiol 76:3425-3441.

Carandini M, Heeger DJ, Movshon JA (1997) Linearity and normalization in simple cells of the macaque primary visual cortex. J Neurosci 17:8621-8644.

Casagrande VA, Norton TT (1991) Lateral geniculate nucleus: a review of its physiology and function. In: Vision and visual dysfunction: the neural basis of visual function, Vol 4, (Leventhal AG, ed), pp 41-84. London: Macmillan.

Celebrini S, Thorpe S, Trotter Y, Imbert M (1993) Dynamics of orientation coding in area V1 of the awake primate. Vis Neurosci 10:811-825.

Cleland BG, Dubin MW, Levick WR (1971) Sustained and transient neurones in the cat's retina and lateral geniculate nucleus. J Physiol (Lond) 217:473-496.

Coenen AML, Vendrik AJH (1972) Determination of the transfer ratio of cat's geniculate neurons through quasi-intracellular recordings and the relation with the level of alertness. Exp Brain Res 14:227-242.

Coenen AML, Gerrits HJM, Vendrik AJH (1972) Analysis of the response characteristics of optic tract and geniculate units and their mutual relationship. Exp Brain Res 15:452-471.

Creutzfeldt O, Ito M (1968) Functional synaptic organization of primary visual cortex neurones in the cat. Exp Brain Res 6:324-352.

Creutzfeldt O, Sakmann B (1969) Neurophysiology of vision. Annu Rev Physiol 31:499-544.

Enroth-Cugell C, Robson JG (1966) The contrast sensitivity of retinal ganglion cells of the cat. J Physiol (Lond) 187:517-552.

Eysel UT, Shevelev IA, Lazareva NA, Sharaev GA (1998) Orientation tuning and receptive field structure in cat striate neurons during local blockade of intracortical inhibition. Neuroscience 84:25-36.

Ferster D (1988) Spatially opponent excitation and inhibition in simple cells of the cat visual cortex. J Neurosci 8:1172-1180.

Ferster D, Miller KD (2000) Neural mechanisms of orientation selectivity in the visual cortex. Annu Rev Neurosci 23:441-471.

Freund TF, Martin KAC, Somogyi P, Whitteridge D (1985) Innervation of cat visual areas 17 and 18 by physiologically identified X- and Y-type thalamic afferents. II. Identification of postsynaptic targets by GABA immunocytochemistry and Golgi impregnation. J Comp Neurol 242:275-291.

Gautrais J, Thorpe S (1998) Rate coding versus temporal order coding: a theoretical approach. Biosystems 48:57-65.

Gawne TJ, Kjaer TW, Richmond BJ (1996) Latency: another potential code for feature binding in striate cortex. J Neurophysiol 76:1356-1360.

Hartline HK (1938) The response of single optic nerve fibers of the vertebrate eye to illumination of the retina. Am J Physiol 121:400-415.

Heeger DJ, Boynton GM, Demb JB, Seidemann E, Newsome WT (1999) Motion opponency in visual cortex. J Neurosci 19:7162-7174.

Heggelund P (1986) Quantitative studies of enhancement and suppression zones in the receptive field of simple cells in cat striate cortex. J Physiol (Lond) 373:293-310.

Herz A, Creutzfeldt O, Fuster J (1964) Statistische Eigenschaften der Neuronaktivität im ascendierenden visuellen System. Kybernetik 2:61-71.

Hirsch JA, Alonso J-M, Reid RC, Martinez LM (1998) Synaptic integration in striate cortical simple cells. J Neurosci 18:9517-9528.

Hopfield JJ (1995) Pattern recognition computation using action potential timing for stimulus representation. Nature 376:33-36.

Hubel DH, Wiesel TN (1959) Receptive fields of single neurons in the cat's striate cortex. J Physiol (Lond) 148:574-591.

Hubel DH, Wiesel TN (1961) Integrative action in the cat's lateral geniculate body. J Physiol (Lond) 155:385-398.

Humphrey AL, Weller RE (1988) Functionally distinct groups of X-cells in the lateral geniculate nucleus of the cat. J Comp Neurol 268:429-447. 
Jones R, Keck MJ (1978) Visual evoked response as a function of grating spatial frequency. Invest Ophthalmol Vis Sci 17:652-659.

Kaplan E, Mukherjee P, Shapley R (1993) Information filtering in the lateral geniculate nucleus. In: Contrast sensitivity, Vol 5 (Shapley R, Lam M-K, eds), pp 183-200. Cambridge, MA: MIT.

Kawano K, Shidara M, Watanabe Y, Yamane S (1994) Neural activity in cortical area MST of alert monkey during ocular following responses. J Neurophysiol 71:2305-2324.

Kiang NY-S, Watanabe T, Thomas EC, Clark LF (1965) Discharge patterns of single fibers in the cat's auditory nerve. Cambridge, MA: MIT.

Kiang NY-S, Lieberman MC, Levine RA (1976) Auditory-nerve activity in cats exposed to ototoxic drugs and high-intensity sounds. Ann Otol Rhinol Laryngol 85:752-768.

Kuffler SW (1953) Discharge patterns and functional organization of mammalian retina. J Neurophysiol 16:37-68.

Lagae L, Raiguel S, Orban GA (1993) Speed and direction selectivity of macaque middle temporal neurons. J Neurophysiol 69:19-39.

Lapicque L (1907) Recherches quantitatives sur l'excitation electrique des nerfs traitée comme une polarisation. J Physiol (Lond) 9:620-635.

Lee BB (1996) Receptive field structure in the primate retina. Vision Res 36:631-644.

Lee BB, Pokorny J, Smith VC, Kremers J (1994) Responses to pulses and sinusoids in macaque ganglion cells. Vision Res 34:3081-3096.

Lennie P (2000) Color vision: putting it together. Curr Biol 10:R589-R591.

Lennie P, Haake W, Williams DR (1991) The design of chromatically opponent receptive fields. In: Computational models of visual processing (Landy MS, Movshon JA, eds), pp 71-82. Cambridge, MA: MIT.

Levick WR (1973) Variation in the response latency of cat retinal ganglion cells. Vision Res 13:837-853.

Levitt JB, Schumer RA, Sherman SM, Spear PD, Movshon JA (2001) Visual response properties of neurons in the LGN of normally-reared and visually-deprived macaque monkeys. J Neurophysiol 85:2111-2129.

Lisberger SG, Movshon JA (1999) Visual motion analysis for pursuit eye movements in area MT of macaque monkeys. J Neurosci 19:2224-2246.

Marvšálek P, Koch C, Maunsell J (1997) On the relationship between synaptic input and spike output jitter in individual neurons. Proc Natl Acad Sci USA 94:735-740.

Mastronarde DN (1987a) Two classes of single-input X-cells in cat lateral geniculate nucleus. I. Receptive field properties and classification of cells. J Neurophysiol 57:357-380.

Mastronarde DN (1987b) Two classes of single-input X-cells in cat lateral geniculate nucleus. II. Retinal inputs and the generation of receptive-field properties. J Neurophysiol 57:381-413.

Maunsell JHR, Gibson JR (1992) Visual response latencies in striate cortex of the macaque monkey. J Neurophysiol 68:1332-1344.

Maunsell JHR, Van Essen DC (1983) Functional properties of neurons in middle temporal visual area of the macaque monkey. I. Selectivity for stimulus direction, speed, and orientation. J Neurophysiol 49:1127-1147.

Maunsell JHR, Ghose GM, Assad JA, McAdams CJ, Boudreau CE, Noerager BD (1999) Visual response latencies of magnocellular and parvocellular LGN neurons in macaque monkeys. Vis Neurosci $16: 1-14$.

McIlwain JT, Creutzfeldt OD (1967) Microelectrode study of synaptic excitation and inhibition in the lateral geniculate nucleus of the cat. J Neurophysiol 30:1-21.

Merrill EG, Ainsworth A (1972) Glass-coated platinum-plated tungsten microelectrode. Med Biol Eng 10:662-672.

Middlebrooks JC, Clock AE, Xu L, Green DM (1994) A panoramic code for sound location by cortical neurons. Science 264:842-844.

Mitzdorf U, Singer W (1979) Excitatory synaptic ensemble properties in the visual cortex of the macaque monkey: a current source density analysis of electrically evoked potentials. J Comp Neurol 187:71-84.

Movshon JA, Newsome WT (1996) Visual response properties of striate cortical neurons projecting to area MT in macaque monkeys. J Neurosci 16:7733-7741.

Movshon JA, Thompson ID, Tolhurst DJ (1978) Spatial summation in the receptive fields of simple cells in the cat's striate cortex. J Physiol (Lond) 283:53-77.

Movshon JA, Adelson EH, Gizzi MS, Newsome WT (1985) The analysis of moving visual patterns. In: Study group on pattern recognition mechanisms (Chagas C, Gattass R, Gross CG, eds), pp 118-151. Vatican City: Pontificia Academia Scientiarum.

Movshon JA, Lisberger SG, Krauzlis RJ (1990) Visual cortical signals supporting smooth pursuit eye movements. In: Cold spring harbor symposia on quantitative biology, Vol LV, pp 707-716. New York: CSH.

Nowak LG, Bullier J (1997) The timing of information transfer in the visual system. In: Cerebral cortex, extrastriate cortex in primates, Vol 12 (Rocklund K, Kaas J, Peters A, eds), pp 205-241. New York: Plenum.

Nowak LG, Munk MHJ, Girard P, Bullier J (1995) Visual latencies in areas V1 and V2 of the macaque monkey. Vis Neurosci 12:371-384.

Nowak LG, Sanchez-Vives MV, McCormick DA (1997) Influence of low and high frequency inputs on spike timing in visual cortical neurons. Cereb Cortex 7:487-501.

O'Keefe LP, Movshon JA (1998) Processing of first- and second-order motion signals by neurons in area MT of the macaque monkey. Vis Neurosci 15:305-317.

Palmer LA, Davis TL (1981) Receptive-field structure in cat striate cortex. J Neurophysiol 46:260-276.

Parker DM, Salzen EA (1977) Latency changes in the human visual evoked response to sinusoidal gratings. Vision Res 17:1201-1204.

Pettigrew JD, Nikara T, Bishop PO (1968) Responses to moving slits by single units in cat striate cortex. Exp Brain Res 6:373-390.

Porter JT, Johnson CK, Agmon A (2001) Diverse types of interneurons generate thalamus-evoked feedforward inhibition in the mouse barrel cortex. J Neurosci 21:2699-2710.

Press HP, Teukolsky SA, Vetterling WT, Flannery BP (1992) Numerical recipes in $\mathrm{C}$, the art of scientific computing, Ed 2. Cambridge: Cambridge UP.

Qian N, Andersen RA (1994) Transparent motion perception as detection of unbalanced motion signals. 2. Physiology. J Neurosci 14:7367-7380.

Raiguel SE, Lagae L, Gulyás B, Orban GA (1989) Response latencies of visual cells in macaque areas V1, V2 and V5. Brain Res 493:155-159.

Raiguel SE, Xiao D-K, Marcar VL, Orban GA (1999) Response latency of macaque area MT/V5 neurons and its relationship to stimulus parameters. J Neurophysiol 82:1944-1956.

Raymond J, Braddick O (1996) Responses to opposed directions of motion: continuum or independent mechanisms? Vision Res 36:1931-1937.

Reid RC, Alonso JM (1995) Specificity of monosynaptic connections from thalamus to visual cortex. Nature 378:281-284

Reid RC, Victor JD, Shapley RM (1992) Broadband temporal stimuli decrease the integration time of neurons in cat striate cortex. Vis Neurosci 9:39-45.

Reid RC, Victor JD, Shapley RM (1997) The use of m-sequences in the analysis of visual neurons: linear receptive field properties. Vis Neurosci 14:1015-1027.

Rockland KS (1995) Morphology of individual axons projecting from area V2 to MT in the macaque. J Comp Neurol 355:15-26.

Sanchez-Vives MV, Nowak LG, McCormick DA (2000) Membrane mechanisms underlying contrast adaptation in cat area 17 in vivo. J Neurosci 20:4267-4285.

Saul AB (1995) Adaptation aftereffects in single neurons of cat visual cortex: response timing is retarded by adapting. Vis Neurosci 12:191-205.

Saul AB, Humphrey AL (1990) Spatial and temporal response properties of lagged and nonlagged cells in cat lateral geniculate nucleus. J Neurophysiol 64:206-224.

Schiller PH (1992) The ON and OFF channels of the visual system. Trends Neurosci 15:86-92.

Schmolesky MT, Wang Y, Hanes DP, Thompson KG, Leutgeb S, Schall JD, Leventhal AG (1998) Signal timing across the macaque visual system. J Neurophysiol 79:3272-3278.

Sestokas AK, Lehmkuhle S (1986) Visual response latency of X- and $\mathrm{Y}$-cells in the dorsal lateral geniculate nucleus of the cat. Vision Res 26:1041-1054.

Shapley RM, Victor JD (1978) The effect of contrast on the transfer properties of cat retinal ganglion cells. J Physiol (Lond) 285:275-298.

Sherman SM, Koch C (1986) The control of retinogeniculate transmission in the mammalian lateral geniculate nucleus. Exp Brain Res 63:1-20

Sillito AM (1975) The contribution of inhibitory mechanisms to the receptive field properties of neurons in the striate cortex of the cat. J Physiol (Lond) 250:305-329.

Singer W, Creutzfeldt OD (1970) Reciprocal lateral inhibition of onand off-center neurones in the lateral geniculate body of the cat. Exp Brain Res 10:311-330.

Singer W, Pöppel E, Creutzfeldt OD (1970) Inhibitory interactions in the cat's lateral geniculate nucleus. Exp Brain Res 14:210-226.

Skottun BC, De Valois RL, Grosof DH, Movshon JA, Albrecht DG, Bonds AB (1991) Classifying simple and complex cells on the basis of response modulation. Vision Res 31:1079-1086.

Snodderly DM, Gur M (1995) Organization of striate cortex of alert, trained monkeys (Macaca fascicularis): ongoing activity, stimulus selectivity, and widths of receptive field activating regions. J Neurophysiol $74: 2100-2125$.

Sutherland NS (1961) Figural aftereffects and apparent size. Q J Exp Psychol 13:222-228.

Sutter EE (1987) A practical non-stochastic approach to nonlinear timedomain analysis. In: Advanced methods of physiological systems modeling, Vol 1 (Marmaerelis V, ed), pp 303-315. Los Angeles, CA: University of Southern California.

Swadlow HA (1995) Influence of VPM afferents on putative inhibitory interneurons in $\mathrm{S} 1$ of the awake rabbit: evidence from cross-correlation, 
microstimulation, and latencies to peripheral sensory stimulation. J Neurophysiol 73:1584-1599.

Tamás G, Buhl EH, Somogyi P (1997) Fast IPSPs elicited via multiple synaptic release sites by different types of GABAergic neurons in the cat visual cortex. J Physiol (Lond) 500:715-738.

Tolhurst DJ, Dean AF (1990) The effects of contrast on the linearity of spatial summation of simple cells in the cat's striate cortex. Exp Brain Res 79:582-588.

Troyer TW, Krukowski AE, Priebe NJ, Miller KD (1998) Contrastinvariant orientation tuning in cat visual cortex: thalomocortical input tuning and correlation-based intracortical connectivity. J Neurosci 18:5908-5927.

Usrey WM, Reppas JB, Reid RC (1998) Paired-spike interactions and synaptic efficacy of retinal inputs to the thalamus. Nature 395:384-387.

Vautin RG, Berkley MA (1977) Responses of single cells in cat visual cortex to prolonged stimulus movement: neural correlates of visual aftereffects. J Neurophysiol 40:1051-1065.

Volgushev M, Vidyasagar TR, Pei X (1995) Dynamics of the orientation tuning of postsynaptic potentials in the cat visual cortex. Vis Neurosci 12:621-628.

von Baumgarten R, Jung R (1952) Microelectrode studies on the visual cortex. Rev Neurol (Paris) 87:151-155.

Wang C, Cleland BG, Burke W (1985) Synaptic delay in the lateral geniculate nucleus of the cat. Brain Res 343:236-245.

Wielaard DJ, Shelley M, McLaughlin D, Shapley R (2001) How simple cells are made in a nonlinear network model of the visual cortex. J Neurosci 21:5203-5211.

Zeki SM (1974) Functional organization of a visual area in the posterior bank of the superior temporal sulcus of the rhesus monkey. J Physiol (Lond) 236:549-573. 